\title{
Transporte naval y envío de flotas comerciales hacia el norte de Europa desde el Cantábrico oriental (1500-1550) ${ }^{1}$
}

\author{
José Damián González Arce y Ricardo Hernández García \\ Universidad de Murcia-Universidad de Valladolid
Naval transport and shipping commercial fleet north of Europe from the eastern Bay of Biscay (1500-1550)

\begin{abstract}
RESUMEN
Un extenso pleito sostenido entre los Consulados de Burgos y Bilbao a mediados del siglo XVI ha permitido conocer el contenido de 68 contratos de fletamento de particulares y de 2 contratos generales para el comercio naval entre los puertos del Cantábrico oriental y distintos puertos de Europa del Norte, especialmente los de Flandes. Esta nueva documentación permite entender mejor muchos aspectos relacionados con

el comercio marítimo de la época: las condiciones de los contratos, los escribanos, comerciantes y armadores que los realizaron; los barcos y las mercancías -incluso las marcas con las que se signaban las sacas -; y los puertos de embarque y destino.
\end{abstract}

\section{PALABRAS CLAVE}

Comercio, transporte naval, pleitos, Burgos, Bilbao.

\section{ABSTRACT}

A long lawsuit held between the Consulates of Burgos and Bilbao in the middle of the XVI century has made possible to know the contents of 68 private contracts of chartering and 2 general contracts for the naval commerce between the eastern Cantabrian ports and some ports of the north of Europe, especially those of Flanders. These new documents let us know better many aspects related to the maritime commerce in that period of time: the conditions of the contracts, the notaries, the merchants and shipowners who made them; the ships and goods -even the marks which they signed the sacks with-; the boarding and destination ports.

\section{KEYWORDS}

Trade, naval transport, lawsuits, Burgos, Bilbao.

\footnotetext{
1 Este artículo ha sido realizado en el marco del proyecto HAR2011-26218, titulado Fiscalidad y sociedad en la Corona de Castilla al sur del Tajo, financiado por el Ministerio de Economía y Competitividad.
} 


\section{INTRODUCCIÓN}

Las características del comercio peninsular con el norte de Europa a través de los puertos del Cantábrico oriental durante la primera mitad del siglo XVI son aún bastante desconocidas. Se tienen nociones generales sobre este sector capital para la economía castellana del período (principales comerciantes y compañías, artículos y géneros intercambiados, volúmenes de tráfico comercial, rutas marítimas, etc.), pero la parquedad de las fuentes no ha permitido a los historiadores conocer los detalles de cómo se desarrolló dicha actividad y su complementario transporte de mercancías vía naval, más allá del marco jurídico con el que se reguló ${ }^{2}$.

En el presente trabajo nos proponemos profundizar en estos aspectos gracias a un extenso pleito sostenido a mediados del siglo XVI entre los Consulados de Burgos y Bilbao por el control del comercio con Europa, resultado del secular enfrentamiento sobre este particular que mantenían ambas localidades desde tiempos medievales ${ }^{3}$. En él se contienen documentos absolutamente inéditos para estos inicios de la Edad Moderna en la zona cantábrica. Caso de 68 contratos de fletamento de particulares, para el envío de sus mercancías a las plazas europeas, y de 2 contratos generales de flete del Consulado de Burgos, para el embarque de flotas conjuntas hacia Flandes, de los que no se conocía ninguno para este período.

A comienzos del siglo XV apareció la Universidad de mercaderes de Burgos, hacia 1480 lo hacía la de Bilbao; en 1494 los Reyes Católicos fundaron el Consulado del mar de Burgos, y en 1511, Juana I, el de Bilbao, ambos herederos y continuadores de sus precedentes gremios de comerciantes o universidades. Estas instituciones suscribieron acuerdos y emitieron ordenanzas que regularon el tráfico comercial con el norte de Europa durante la primera mitad del siglo XVI y fueron el resultado de su enfrentamiento por el control del mismo. En 1499 y 1500 ambas partes firmaron dos compromisos para acabar con sus disputas, mediante una concordia que fijaba los fletes, las jurisdicciones, las averías, las flotas, las mercancías... No obstante, no terminaron ahí las luchas, lo que hizo necesario un nuevo y definitivo convenio en 1513, que suponía el triunfo de Burgos. Se respetó durante los 20 años para los que fue estipulado, y fue prorrogado en 1533 por otros 25 , con algunas modificaciones menores ${ }^{4}$.

2 BILBAO, Luis María y LANZA GARCÍA, Ramón, «Entre Castilla y Francia: Comercio y comerciantes en Bilbao a mediados del siglo XVI», Revista de Historia Económica, 27,1 (2009), pp. 103-140.

3 Archivo General de Simancas (A.G.S.), Consejo Real de Castilla (C.R.C.), 204.

${ }^{4}$ GONZÁLEZ ARCE, José Damián, «La ventaja de llegar primero. Estrategias en la pugna por la supremacía mercantil durante los inicios de los consulados de Burgos y Bilbao (1450-1515)», Miscelánea Medieval Murciana, 33 (2009), pp. 77-97. GONZÁLEZ ARCE, José Damián, «La universidad de mercaderes de Burgos y el consulado castellano en Brujas durante el siglo XV», En la España Medieval, 33 (2010), pp. 161-202. Si bien en los trabajos anteriores, siguiendo los estudios sobre el Consulado de Bilbao de comienzos del siglo XVI, se apunta el año 1489 como el de fundación de la Universidad, su antecedente, lo cierto es que en un documento de 1487 los Reyes Católicos se refieren a Lope de Reinaga, 
El arreglo fue roto por la oposición de Bilbao a que Burgos siguiese ostentando la primacía en los fletes. Por ello el Consulado de la segunda comenzó negociaciones con Portugalete para trasladar a su puerto los embarques. En 1547 se firmó un tratado entre ambas localidades cuyas cláusulas nos recuerdan las suscritas en 1499-1500 entre Burgos y Bilbao. El delegado del Consulado de la primera era el encargado de contar en Portugalete las averías comunes y gruesas ante un escribano de la villa. Se abonaría 1 maravedí por saca de lana, y a ese mismo respecto para otras mercancías, con destino a la iglesia de Santa María, así como un ducado para la obra de los muelles. La mitad de los fletes con destino a Flandes se harían desde dicho fondeadero.

Este nuevo pacto dio lugar a una serie de pleitos entre Bilbao y Burgos. En uno de ellos, originado por el secuestro de 6 naos gruesas con lana que los de Portugalete embargaron para reembarcarlas en su amarradero con destino a Flandes, los bilbaínos acusaron a los burgaleses y portugalujos de haber realizado un monipodio y confederación, prohibidos por ley, cuyo resultado fue el boicot a sus comerciantes; contra el que reclamaron, alegando que nunca estuvieron obligados a cumplir las ordenanzas del Consulado de Burgos. Tras una sentencia favorable a Bilbao de 1551, el proceso pasó al Consejo Real, mientras que la guerra con Francia hizo que se llegase a una nueva concordia en 1553, que nuevamente ponía paz entre las partes ${ }^{5}$.

\section{LAS CONDICIONES DE LOS FLETES}

La normativa que reguló el transporte marítimo del Cantábrico oriental durante la primera mitad del siglo XVI fueron las ordenanzas del Consulado de Burgos de 1511, incluidas íntegras en las generales, aparecidas en 1538, que apenas innovaron en esta materia ${ }^{6}$, así como la primera ordenanza emitida por éste en 1499, que se aplicaba desde tiempo inmemorial, para el embarque conjunto de la flota. Veamos cómo se siguieron en la práctica.

En una fecha indeterminada del siglo XVI el Consulado de Burgos elevó un alegato a la Corona. En él exponía los inconvenientes de aplicar la pragmática que otorgaba preferencia de carga a las naves mayores sobre las menores en el transporte de lanas a Flandes, en contra de sus ordenanzas de 1511. Así, para fletar las dos flotas anuales, en torno a los meses de marzo y septiembre, que estaban

cónsul de los maestres de las naos de la villa de Bilbao, y por tanto cargo directivo de la antedicha Universidad de mercaderes y navieros de la localidad; el cual reclamó de los monarcas que ordenase al concejo de la villa que no aumentase el pedido sobre las naos y carabelas de la misma, tal y como los repartidores habían hecho el año anterior (A.G.S., Registro General del Sello [R.G.S.], 1487-04, 118).

5 BASAS FERNÁNDEZ, Manuel, El Consulado de Burgos en el siglo XVI, Madrid, CSIC, 1963, pp. 42-45. GUIARD Y LARRAURI, Teófilo, Historia del Consulado y casa de Contratación de Bilbao y del comercio de la villa de Bilbao: 1511-1699, Bilbao, 1913, pp. 3-35.

6 BASAS FERNÁNDEZ, M., op. cit., 158-159. 
comprendidas por entre 15 y 20 buques de unos 200-300 toneles, se hacía acudir a la ciudad de Burgos a sus maestres, con los que se asentaban todo tipo de acuerdos para garantizar el transporte, puesto que en ellas se invertía casi todo el dinero de los vecinos de Burgos, Segovia, Castrogeriz y otras localidades que trataban con lanas. La primera de las condiciones era que todas las naves viajasen juntas, fijándose la artillería, munición, gentes de armas y armamento que debía llevar cada una en función de su tamaño, así como los víveres. En segundo lugar, se acordaba el flete de cada barco, las costas de las sacas y las de otras mercancías. Los maestres se comprometían a observar estos acuerdos y regresar a la costa castellana con las de retorno que les fuesen dadas en Flandes por los cónsules de la nación de España residentes en Brujas, con los que los burgaleses se habían concertado para los fletamentos. Para ello los maestres depositaban fianzas en Burgos, mientras que el Consulado les otorgaba garantías de abonarles los fletes ${ }^{7}$.

Las ordenanzas de 1538 del Consulado determinaron con más detalle cómo se debían organizar los embarques, completando lo dispuesto en las de 1499 y 1511. El prior y cónsules trataban directamente con los dueños y maestres de las naos y carabelas para discutir las condiciones generales, encomendarles un buen trato a las mercaderías y encargarles el cobro de las averías de la Universidad. Para ello habían de conocer y seleccionar a los mejores, dándoles premios por sus servicios; la elección de éstos y sus navíos tenían que atender al interés general y no a ruegos o comisiones. Para las averías, consignadas en las cartas de fletamento, se debía hacer constar la condición de que los maestres cuando llegasen al fondeadero de destino habían de dar al bolsero de la Universidad las que le correspondían, incluidas en las costas del flete, y al que no las pagase se le podría retener el cargamento a bordo. Los regidores de la Universidad debían hacer que los maestres entregasen las mercancías a sus consignatarios; así como exigirles fianzas, a depositar en Burgos, según su criterio. Suscritos estos acuerdos generales con los armadores, el prior y cónsules enviaban a los surgideros a unos comisarios con el cometido de visitar los buques, cargazones y marineros; revisar las cartas de fletamento, para que no llevasen menos tripulantes ni armamento de los contemplados en ellas; ver si iban artículos en lugares no permitidos; contrastar los registros de los escribanos de a bordo para comprobar que no se contenía más carga de la debida; y, finalmente, contar las averías comunes y gruesas repartidas sobre lo embarcado, que debían cobrar. Junto a estos comisarios o delegados del Consulado actuaban los huéspedes y encomenderos, delegados por los mercaderes para velar por su género durante la estiba, el transporte o en su recepción, quienes, junto a los del Consulado, participaban en el reparto de las

\footnotetext{
7 GONZÁLEZ ARCE, J. D., «La ventaja...», 95. En 1496 los Reyes Católicos ordenaron que los extranjeros manifestasen en los puertos de arribada las mercancías que importaban para exportar productos nacionales por el mismo valor, dando fianzas que garantizasen que cumplirían con esta obligación; también quedó expresamente prohibida la salida de dinero y cosas vedadas, como en tiempos anteriores (A.G.S., R.G.S., 1496-05, 146).
} 
averías. Al margen de las armadas únicas, en tiempos de paz se podían fletar barcos individualmente en cualquier época del año para llevar otros artículos que no fuesen lanas ni hierro, que irían a su albedrío y costearían sus propios gastos de defensa.

Además de las condiciones generales concertadas por la Universidad de Burgos con los armadores para la contratación conjunta de todos los buques y los fletes de las flotas, cada mercader debía suscribir individualmente con los de su elección, armador y buque, una serie de acuerdos para el traslado de sus mercancías. Éstos eran reflejados en el contrato de fletamento o carta de flete, que era uno de los documentos esenciales para el transporte marítimo, junto a la cargazón y el conocimiento. La primera también se podía denominar carta de flete y averías porque solía consignar éstas. La segunda consistía en una especie de factura dirigida al consignatario. Mientras que el conocimiento era el recibo de carga expedido por el patrón o maestre de la nave.

Los fletes, o importes del viaje, se hacían efectivos una vez arribada la nave al embarcadero de destino, esto es, una vez cumplida la carta de flete, y lo abonaba el consignatario de la mercancía; quien también podía entregar al patrón una letra de cambio que sería cobrada a su retorno al amarradero de partida. El precio de los fletes estaba fijado por el Consulado según dos variedades, el de la nave completa, o una cantidad por tonelada, y el de carga parcial, a partir de un tanto por saca o fardel embarcado; solamente se conservan estas tasas para la segunda mitad del siglo $\mathrm{XVI}{ }^{8}$.

Se pueden distinguir tres clases de averías. Una primera era la gremial, o cuota que los miembros de las universidades debían satisfacer de forma fija. La segunda era la propia del seguro marítimo, o avería-daño. Y, la tercera, la derivada de los fletes, avería-flete, comunes o gruesas, que eran variables.

Las averías gremiales fueron las contribuciones que los miembros de los consulados aportaban para su sostenimiento. Práctica común en la Universidad de Burgos antes de la aparición de su Consulado. Cuya pragmática fundacional de 1494 la facultaba para fiscalizar anualmente las cuentas de estas cuotas de sus consulados en el extranjero. Luego la declaratoria de 1495 hizo lo propio con la Universidad de Bilbao. Aspectos posteriormente recogidos y delimitados por los acuerdos de 1499-1500 de ambas instituciones, así como en las ordenanzas del Consulado de Burgos de 1538 y 1572; mientras que en 1514 la reina Juana ratificó la potestad de la Universidad de Burgos de exigir averías entre sus socios. Su destino era abonar los salarios de sus figuras rectoras (prior, cónsules, diputados, escribanos...); así como despachar correos, fletar las flotas, armarlas, pagar pleitos, reparar puentes y caminos y sufragar misas y limosnas. Su pago se hacía a final de año, en función del volumen de cuentas de cada miembro de la Universi-

8 BASAS FERNÁNDEZ, M., op. cit., 161-168. Ordenanzas del Consulado de Burgos, Valladolid, 1988, ff. 28r-34r. 
dad, a partir de sus libros de cargazón. Los aranceles conocidos que contenían estos derechos fijos por mercancía embarcada son el de las ordenanzas del Consulado de Brujas de 1441 y los de Burgos de 1538, que era el antiguamente seguido por la Universidad, y 1572.

Aparte de las averías de la Universidad, de las que se podían sufragar algunos gastos hechos en el despacho de las flotas, como salarios de los delegados del Consulado, las que aquí más nos interesan, por constar en las cartas de fletamento, son las averías-flete, que eran repartidas por dichos delegados a los maestres de las naves en presencia de los huéspedes de los comerciantes. Las comunes, en Burgos servían para equipar cada barco con los aparejos que precisase, mientras que las gruesas se destinaban a reforzarlos con artillería y gentes de armas; aunque las ordenanzas del Consulado de Bilbao de 1517 y 1737 especifican que las comunes eran para los gastos menudos de las embarcaciones (pilotajes de costas y puertos, o lemanes, atoajes, gabarras, etc.), mientras que las gruesas podían ser, entre otras, el resultado de los daños infligidos a un navío (en cordajes, velas, mástiles, etc.) o su carga (que podía ser arrojada) para librarlo de un naufragio. En los contratos de flete, que luego analizaremos, son éstas últimas las que predominan casi de forma absoluta; de manera que el armador proveía a la nave de los aparejos y el mercader debía correr, casi siempre en solitario, con los gastos de lemanes y guindajes (estiba con grúas), a modo de averías comunes, que podían variar en cada puerto de embarque. De otro lado, las gruesas (contrato 28 del apéndice) también eran las que se producían por percanes durante el viaje, cuyo reparto entre las pares quedaba a veces estipulado en la carta, puesto que la artillería y armamento de la tripulación solían correr por cuenta del dueño o maestre del barco.

Los delegados del Consulado de Burgos podían recaudar las averías a priori, para armar las naves, o entregar letras de cambio para que fuesen abonadas a los maestres a su llegada a Flandes por el Consulado de Brujas; de ahí que fuesen variables, en función de los gastos a realizar en el flete de cada nave o los que resultaban de su travesía, a repartir entre la mercancía, y que se consignasen en las cartas de fletamento. En caso de naufragios, secuestro de naves en tiempo de guerra o asaltos de piratas también se podían derramar averías extraordinarias $^{9}$.

Contamos con un ejemplo documentado de cómo se realizaban los fletes colectivos del Consulado de Burgos, en concreto el del año 1547, gracias a un proce-

\footnotetext{
9 BASAS FERNÁNDEZ, M., op. cit., 130-146, 167-171. GONZÁLEZ ARCE, J. D., «La ventaja...». VAS MINGO, Marta Milagros del y LUQUE TALAVÁN, Miguel, «La avería de disminución de riesgos marítimos y terrestres. La avería del camino", Estudios de Historia Novohispana, 26 (2002), pp. 132-137. Ordenanzas..., ff. 22v-25r, 27v-28r, 32r-v. GUIARD Y LARRAURI. T., op. cit., pp. 86-93. Los Códigos españoles. Concordados y anotados. XII. Nueva Recopilación. Autos Acordados. Ordenanzas de Bilbao, Madrid, 1851, pp. 486-490. En los contratos de flete se dice que las «averías de España» (comunes) comprendían pólvora, sebo, costados, y tillados; aparte, el comerciante contratante de la nave, debía pagar los gastos de lemanes, pequeños lemanes y atoajes.
} 
so judicial por confiscación de 10 embarcaciones en el puerto de Portugalete, que supuso el inicio del pleito entre Burgos y Bilbao ${ }^{10}$. La parte demandante, el Consulado de Burgos, pidió a un juez ordinario de Portugalete que embargase a los mercaderes Rodrigo de Soria, Antonio y Domingo de Yanguas y Alonso Ruiz, vecinos de Logroño, y a sus consortes de Vitoria, Nájera y Torrecilla ${ }^{11}$; y, junto a ellos, a los bilbaínos Juan de Amezaga, Juan de Zornoza, Juan de Catelinaga, Domingo de Larrauri, Juan de Baracaldo, Pedro de Bermeo, Juan Martínez de Goiri y Mateo de Aya, maestres de las naos fletadas por los antedichos comerciantes, de las que habían sido requisadas algunas sacas de lana, así como velas de las naves. En otra parte se cita junto a los anteriores 8 maestres a Martín de Bertendona, Martín Ortiz de Orozco, Jacobe de Agurto, Alonso de Vitoria, Juan de Zuazo y Juan de Zeberio. A este pleito inicial, librado en primera instancia por un alcalde portugalujo, y luego por el corregidor de Vizcaya, se sumó posteriormente el ConsuladoUniversidad de Bilbao, así como la propia villa, del lado de los mercaderes y maestres, contra el de Burgos, y pasó, en grado de apelación, a la Chancillería y al Consejo Real.

Los argumentos esgrimidos para el citado embargo fueron las aludidas ordenanzas confirmadas por los reyes, según las cuales competía al Consulado de Burgos determinar en qué barcos y por qué puertos se debían embarcar las lanas rumbo a Francia, Flandes o Inglaterra, de manera exclusiva, sin que pudiese hacerse al margen del mismo. De forma que ningún mercader de Segovia, Logroño, Nájera, Valladolid, Medina de Rioseco, Castrogeriz, Palenzuela u otros lugares podían cargar sus mercaderías fuera de los navíos designados; bajo pena de 2 ducados por saca, idéntica a la que se impondría a los dueños de los buques, la mitad para el hospital de S. Juan de Burgos, la otra para la Universidad de mercaderes de la ciudad.

De este modo, el alcalde de Portugalete se personó en los barcos donde procedió a requisar las siguientes cosas: En la nao de Juan de Zornoza y Bartolomé de Miranda, que era de menos de 200 toneles, confiscó aparejos y sacas de lana hasta completar el valor de 2 ducados por cada saca, de las 700 indebidamente embarcadas, pues dicha nave no pertenecía a la flota fletada por el Consulado. En concreto aprehendió el papahígo del trinquete, el mayor, con su boneta, así como la vela de gavia mayor y la de la mesana; además del velamen, tomó 22 sacas de lana, de las cuales el escribano anotó las marcas con que iban rotuladas e identificaban a sus dueños (en total 9 marcas de otros tantos propietarios, que aquí no

\footnotetext{
10 A.G.S., C.R.C., 204, 3-2.

${ }^{11}$ Dichos consortes eran, según consta en otras partes del pleito: Pedro de Enciso, Luis de Sesma, Juan de Montenegro, Andrés Gallego, Juan de Cabezón, Francisco Tajador y Juan de Bazán, de Logroño; Martín González de Castejón, de Ágreda; Juan de Oipa y Francisco de Ali, de Vitoria; Juan y Diego de Anguiano y Diego de Villanueva, de Santo Domingo de la Calzada; Fernán González y Diego González, de Torrecilla de los Cameros; Francisco de Valdivieso, de Sigüenza. El huésped y encomendero (quien acompañaba la mercancía) de todos ellos era Martín de Bertendona (A.G.S., C.R.C., 204, 3-4, fol. 109r-v).
} 
recogemos porque no aparecen identificados). De la nao de Juan de Catelinaga y Lope de Zaldívar embargó el antedicho velaje y 14 sacas (de 4 marcas diferentes, 2 de ellas presentes en la anterior embarcación). De la de Juan de Amezaga y Domingo de Larrauri decomisó similares trapos y 11 sacas (de 3 marcas, alguna de ellas también repetida). Todo ello lo entregó al preboste de la villa, para que lo custodiase. Por la embarcación de Juan Martínez de Goiri y Juan de Zeberio declaró su contramaestre, y dijo que llevaba 850 sacas con destino a Flandes, propiedad de los susodichos mercaderes; tras lo cual el alcalde procedió a aprehender el velamen, 13 sacas de lana (de 10 marcas, algunas iguales a las anteriores), 1 fardo de peletería y otro de frazadas.

Posteriormente, en un interrogatorio, Juan de Catelinaga declaró que era el dueño de la nao San Juan, que contenía 800 sacas de lana con destino a Flandes y que había sido fletada por mercaderes de Vitoria y Logroño (Martín de Bertendona, Bartolo de Catelinaga, Sancho de Larrauri, Juan de Quijano, Pedro López de Arbolancha y un criado de Pedro Ortiz de Bilbao); al margen, por tanto, de la universidad de Burgos, y porque el fiel y diputados de la de Bilbao se lo habían rogado, recordándole el daño que suponía para los navíos bilbaínos que la Universidad de Burgos no contase con ellos para sus embarques generales. San Juan de Amezaga manifestó ser propietario de la nao La Trinidad, junto a Domingo de Larrauri, que cargaba 1.450 sacas de lana con rumbo a Flandes, que había recogido en Bilbao de los huéspedes de algunos tratantes de Vitoria y Logroño (más o menos los antedichos); además arguyó que había ido unas 5 veces a Burgos a solicitar que contratasen su barco y no lo había conseguido, sino que los de la Universidad habían hecho ordenanzas para no emplearlos bilbaínos ni cargar mercancías en ese puerto, e incluso los cónsules de Burgos habían tomado juramento a los dueños de las embarcaciones del fletamento general para asegurarse de que no tenían intereses ni negocios comunes con los bilbaínos. Juan de Zornoza, poseedor de La Concepción de Nuestra Señora, conjuntamente con Juan de Baracaldo y Pedro de Alvia, declaró llevar en ella 625 sacas de lana, pertenecientes a los citados comerciantes; con argumentos similares a los anteriores sobre el boicot ejercido por Burgos a Bilbao y sus navíos.

Para probar que las sacas requisadas fueron cargadas al margen del embarque general organizado por la Universidad, ésta aportó testimonios notariales, fechados en Burgos, en octubre de 1547, en los que constan algunos detalles del mismo. Se trata de una de las escasas referencias conocidas a este tipo de contratos $^{12}$. Mediante el primero, el prior, Juan de Castro, a la sazón regidor de la ciudad, y los cónsules Jerónimo Pardo Orense y Nicolás Astudillo, presentaron la carta del fletamento general efectuado en los meses de mayo y junio por los ante-

\footnotetext{
12 M. BASAS FERNÁNDEZ (op. cit., 167-168), en su obra sobre el Consulado de Burgos señala no haber encontrado ninguno, aunque reproduce otra referencia similar a la aquí contenida, el fletamento de 1558, con 20 naves y 16.083 sacas. En su día T. GUIARD Y LARRAURI (op. cit., 124-126) aportó los de 1568 y 1571 .
} 
riores prior, Gómez de Quintanadueñas, y cónsul, Bernardino de Salamanca, redactada por un escribano de Burgos. En ella consta que fueron 9 las naos empleadas para llevar la lana desde Portugalete y Deva a Flandes:

Tabla 1: Fletamento general de los meses de mayo-junio de 1547 del Consulado de Burgos

\begin{tabular}{|c|c|c|c|c|}
\hline N. & Propietario & Maestre & Nao & Sacas \\
\hline 1 & Antón Pérez de Coscojales & Bernabé de Galdames & Los 3 Reyes & 950 \\
\hline 2 & \multicolumn{2}{|c|}{ Juan de Montellano } & $\begin{array}{c}\text { Santa María } \\
\text { de Portugalete }\end{array}$ & 1.000 \\
\hline 3 & Juan de Ugarte & Santa María & 1.100 \\
\hline 4 & Sancho de la Pedriza & Santiago & 750 \\
\hline 5 & Ochoa de Larrea & Pedro del Nocedel & $\begin{array}{c}\text { Santa María } \\
\text { de Portugalete }\end{array}$ & 800 \\
\hline 6 & Juan de Montellano & Martín de Montellano & El Santo Crucifijo & 800 \\
\hline 7 & Pedro Ortiz de Archiniega & Pedro de Ozandía & Santiago & 650 \\
\hline 8 & \multicolumn{2}{|c|}{ Pedro de Santurce (Portugalete) } & La Trinidad & 450 \\
\hline 9 & \multicolumn{2}{|c|}{ Juan de Herrada (Portugalete) } & La Trinidad & 750 \\
\hline
\end{tabular}

En la segunda carta de fletamento general, también suscrita por el prior Quintadueñas, se diferencian las naves según el surgidero de embarque, Portugalete o Santander, con destino Ramua (Arnemuiden, en Zelanda), La Esclusa (Sluis, cerca de Brujas) o Amberes. Este documento, aunque no se dice, debió corresponder a una segunda flota formada en los meses de septiembre y octubre, cuando ya había concluido la campaña veraniega de recogida de la lana y se precisaba mayor número de embarcaciones para transportarla a Flandes:

Tabla 2: Fletamento general de los meses de septiembre-octubre de 1547 del Consulado de Burgos

\begin{tabular}{|c|c|c|c|c|}
\hline N. & Propietario & Maestre & Nao \\
\hline \multicolumn{5}{|c|}{ PORTUGALETE } \\
\hline 1 & $\begin{array}{c}\text { Pedro Ortiz de Archiniega } \\
\text { (Portugalete) }\end{array}$ & 1.100 \\
\hline 2 & Ochoa de Capetillo & $\begin{array}{c}\text { La Barca } \\
\text { de la Concepción }\end{array}$ & 650 \\
\hline 3 & Antón Pérez de Coscojales & Pedro Ortiz de Vergareda & La Concepción & 800 \\
\hline 4 & Pedro del Casal & Martín de Santurce & San Bernabé & 600 \\
\hline 5 & Martín Ortiz de Martiato & Ochoa Ortiz de Martiato & $\begin{array}{c}\text { Nuestra Señora } \\
\text { de la Piedad }\end{array}$ & 800 \\
\hline 6 & \multicolumn{2}{|c|}{ Juan de Rebonza (Sestao) } & San Nicolás & 350 \\
\hline
\end{tabular}


JOSÉ DAMIÁN GONZÁLEZ ARCE Y RICARDO HERNÁNDEZ GARCÍA

\begin{tabular}{|c|c|c|c|c|}
\hline N. ${ }^{\circ}$ & Propietario & Maestre & Nao & Sacas \\
\hline \multicolumn{5}{|c|}{ SANTANDER } \\
\hline 7 & \multicolumn{2}{|c|}{ Martín de Amezaga (Placencia) } & La Concepción & 1.100 \\
\hline 8 & \multicolumn{2}{|c|}{ Juan Inglés (Placencia) } & La Concepción & 400 \\
\hline 9 & \multicolumn{2}{|c|}{ Lope García de Terreros } & Santa Clara & 750 \\
\hline 10 & Juan Ochoa de Basabe & Juan de Tellaeche & La Magdalena & 800 \\
\hline 11 & Juan de Bayona & Sancho Descata & La Trinidad & 750 \\
\hline 12 & Fernando de Artieta & Juan Ruiz de Adorriaga & San Julián & 550 \\
\hline 13 & \multicolumn{2}{|c|}{ Fernando de Artieta } & Santa Bárbara & 1.100 \\
\hline 14 & \multicolumn{2}{|c|}{ Martín Juan de Aróztegui } & San Cristóbal & 1.100 \\
\hline 15 & \multicolumn{2}{|c|}{ Diego de Uruña (Santander) } & $\begin{array}{l}\text { Santa María } \\
\text { de la Cruz }\end{array}$ & 1.100 \\
\hline 16 & \multicolumn{2}{|c|}{ Juan de Larrea (Castro Urdiales) } & San Jerónimo & 400 \\
\hline 17 & $\begin{array}{l}\text { Francisco de Bolívar } \\
\text { (Santander) }\end{array}$ & Toribio de Bolívar & $\begin{array}{c}\text { Concepción } \\
\text { del Espíritu Santo }\end{array}$ & 550 \\
\hline 18 & \multicolumn{2}{|c|}{ Martín de Olarte } & Santiago & 550 \\
\hline 19 & Pedro González de Escalante & Pedro de Berategui & La Madre de Dios & 1.100 \\
\hline 20 & \multicolumn{2}{|c|}{ Francisco Cachopín (Laredo) } & $\begin{array}{l}\text { La Ascensión de Nues- } \\
\text { tra Señora }\end{array}$ & 550 \\
\hline 21 & Juan de Ullada (Laredo) & Pedro Cachopín & $\begin{array}{l}\text { La Concepción de } \\
\text { Nuestra Señora }\end{array}$ & 550 \\
\hline 22 & \multicolumn{2}{|c|}{ Juan Cachopín (Laredo) } & $\begin{array}{l}\text { La Ascensión de Nues- } \\
\text { tra Señora }\end{array}$ & 800 \\
\hline 23 & \multicolumn{2}{|c|}{ García de Escalante } & La Madre de Dios & 1.100 \\
\hline 24 & \multicolumn{2}{|c|}{ Sancho de Brueco (Baracaldo) } & San Vicente & 700 \\
\hline 25 & Andrés de Arbreto (Deusto) & Pedro de Tellaeche & $\begin{array}{l}\text { La Concepción de } \\
\text { Nuestra Señora }\end{array}$ & 700 \\
\hline 26 & \multicolumn{2}{|c|}{ Diego de Decedo (Castro Urdiales) } & El Espíritu Santo & 900 \\
\hline 27 & \multicolumn{2}{|c|}{ Jacobe de Ugaz } & Santa María & 1.100 \\
\hline 28 & $\begin{array}{c}\text { Juan Martínez de Líbano } \\
\text { (Bermeo) }\end{array}$ & Pedro de Urquice & La Trinidad & 1.100 \\
\hline
\end{tabular}

En total, se trata de 37 barcos con 29.300 sacas de lana. Un número muy similar a las que se contienen en los registros burgaleses de averías para las judicaturas $1546-1547$ (34 navíos y 31.028 sacas) y 1547-1548 $(41,36.690)^{13}$.

Trasladado el pleito a la jurisdicción del corregidor de Vizcaya, éste ordenó levantar el decomiso de los aparejos y mercancías y devolverlos a los mercaderes

13 CASADO ALONSO, Hilario, «El comercio internacional burgalés en los siglos XV y XVI», en Actas del V Centenario del Consulado de Burgos, Burgos, Diputación, 1994, vol. I, pp. 175-247. 
y navieros enfrentados al Consulado de Burgos, mientras que éstos se comprometieron a abonar las multas en las que habían incurrido.

\section{CONTRATOS DE FLETAMENTO}

Como hemos dicho, las cartas de flete constituían el contrato con las condiciones particulares suscritas entre comerciante y armador. Veamos qué información aportan las conservadas en el pleito de 1547-1549 ${ }^{14}$.

Antes conviene aclarar por qué fueron incorporadas al mismo. En 1549, el emperador Carlos autorizó a la Universidad de Bilbao a acudir ante los escribanos que durante los 40 años anteriores habían redactado los contratos de fletamento en los puertos de las cuatro villas (San Vicente de la Barquera, Santander, Laredo y Castro Urdiales), Vizcaya y Guipúzcoa entre comerciantes y armadores para aportarlos como prueba. De modo que 68 de ellos son reproducidos entre la documentación del caso, relativos a los años comprendidos entre 1504, el más antiguo, y 1549, los más modernos. Si los notarios son los mismos que actuaron en su día, las copias de las cartas de flete aparecen firmadas por ellos mismos, si no, las reproducciones son suscritas por los que realizaron su traslado, que son los que heredaron las escribanías de los primeros. Con ellas se quería argumentar que las ordenanzas que Burgos esgrimió para el embargo de 1547 no eran cumplidas desde tiempo atrás, sino que habían caído en desuso, de manera se podían fletar naves en cualquier parte sin contar con su Universidad.

En las citadas cartas consta la fecha de suscripción, el escribano real o del número y los datos de los contrayentes, nombres del mercader contratante, o fletante, y del maestre de la nave, o fletador, así como la vecindad de ambos. También se recogen, a veces, las características del navío, nombre, clase, tonelaje, tripulación (marineros, grumetes y pajes), armamento y piezas de artillería. También aparece el destino del cargamento, puerto y país, el embarcadero de salida y el de carga, en caso de que no fuese el mismo; pues hay que tener en cuenta que las flotas conjuntas partían de un mismo fondeadero pero los barcos podían ser previamente cargados en otros antes de acudir al de salida; otras veces las mercancías podían ser llevadas en barcas desde surgideros de menor calado, como Bilbao o San Sebastián, para estibarlas en naves de mayor tonelaje que no podían atracar en ellos y esperaban en otros como Portugalete o Pasajes. En ocasiones eran fijadas las rutas a seguir y las escalas. Asimismo, incluían, como es lógico, cuál era la carga, su cantidad, los símbolos o marcas con que iban rotuladas las sacas que la contenían (primeras imágenes de marca o logotipos empresariales de la historia, directamente relacionadas con las señales gremiales) ${ }^{15}$, su plazo

\footnotetext{
14 A.G.S., C.R.C., 204, 3-3.

15 Está por hacer una historia de las marcas comerciales (marquismo), como imagen o logotipo representativo de una compañía, negocio, empresa o taller, desde sus orígenes gremiales más remotos,
} 
de salida desde la llegada al puerto de embarque, el pago del flete por unidad cargada en la moneda del país de arribada, o en otra, el plazo de tiempo en que se haría efectivo el mismo tras la llegada y las averías a abonar. A veces constaba también el lugar donde debía viajar el género, en cubierta, el menos delicado, o en la bodega, el más sensible, y sus consignatarios, agentes o factores a los que se debía hacer entrega de éste. Algunos contratos contienen también las condiciones a aplicar a la mercancía de retorno, en qué consistía y su cantidad, los amarraderos de embarque y destino, los fletes a abonar por ella y los consignatarios a quienes debía ser entregada.

Veamos con más detalle algunos de los aspectos más relevantes.

\subsection{Escribanos}

Suelen ser los mismos en cada localidad, lo cual apunta a dos cosas. Bien a que se estaba produciendo una especialización que con el tiempo conduciría al escribano de marina, o único en cada puerto para este tipo de contratos. Bien a que los representantes del Consulado de Bilbao seleccionaron a aquéllos en cuyas notarías se hubiesen registrado mayor cantidad de cartas de flete, por una cuestión de comodidad. La tabla del apéndice ha sido elaborada a partir de cómo aparecen recopiladas éstas en el pleito, es decir, por escribanos; de los cuales 2 son de Deva (con 6 en total), otros 2 de Bilbao (con 28) y 5 de San Sebastián (con 34).

Según el traslado del contrato de 1504, al notario de San Sebastián, Miguel de Tolosa, ante quien fue suscrito, le sucedió en la escribanía Pedro de Igueldo, del que tenemos 8 cartas; la copia de todas ellas fue sacada por el continuador de éste, Martín Pérez de Arbeláiz, de quien contamos con otras 4. Pedro de Sagastizar, igualmente donostiarra, realizó entre 1525-1529 6 acuerdos, luego copiados por su sucesor, Juan López de Sur. Otro de los fedatarios de San Sebastián, Nicolás de Plazaola, alegó contar en sus archivos con más, aparte de los 15 aportados al pleito, asy pasados en mi presençia como ante otros escriuanos en cuyos registros yo subçedí. Las 6 actas de Deva fueron redactadas por los que pudieron ser dos notarios hermanos, Juan Pérez de Arriola y Sebastián de Arriola. El escribano de Bilbao Jacobe Martínez de Gueldo fue sucedido por Jacobe de

tanto individuales (caso de las marcas de cantero), como colectivos (el emblema gremial de cada corporación local), hasta las marcas comerciales del mundo actual; pasando por las marcas de los libreros, las de agua del papel y estas pioneras de compañías comerciales. Para un primer estudio de conjunto, ALVARDO PLANAS, Javier, Heráldica y usos tradicionales de las corporaciones de oficio: Las marcas de canteros, Madrid, Ediciones Hidalguía, 2009. Para algunos ejemplos de marcas de mercaderes aisladas, PRIOTTI, Jean-Philippe, Los Echávarri, mercaderes bilbaínos del siglo de oro: ascenso social y económico de una familia, Bilbao, Diputación Foral de Bizkaia, 1996, pág. 149. GUIARD Y LAURRARI, T., op. cit., XCVI, 73, 77. GUIARD Y LARRAURI, Teófilo y RODRÍGUEZ HERRERA, Ángel, Compendio e índices de la historia de la noble villa de Bilbao, Bilbao, Caja de Ahorros Municipal, 1978, p. 30. 
Arrieta, y éste, a su vez, por Domingo de Olagorta, que por tanto fue el encargado de copiar los 4 contratos de fletamento del pleito para el Consulado de Bilbao. Mientras que al también bilbaíno Fortún Martínez de Bilbao La Vieja le sucedió su hijo, Juan de Bilbao La Vieja, quien copió sus 24 documentos.

\subsection{Mercaderes, compañías y marcas}

Entre los mercaderes firmantes de los contratos destacan, por número, los que eran vecinos de San Sebastián, unos 33. Algunos de ellos signatarios de más de una de las cartas de flete, como Luis Cruzad. Le siguen en importancia, por el número, los bilbaínos, unos 23; y, a gran distancia, los logroñeses, vitorianos y pamploneses. Si en su mayoría se trata de contratos de barcos para el transporte de las mercancías de los fletantes, muchas de las actas de fletamento fueron suscritas por mercaderes en nombre de otros, con los que formaban compañías estables o uniones temporales, solamente con la intención de fletar el navío. Se trató de comerciantes cargadores que sirvieron de intermediarios para dar salida/entrada a los artículos de otros del interior, de las zonas de Álava, La Rioja y Navarra, que por ello escogieron como socios, preferentemente, a estos radicados en las costas guipuzcoanas. Tal y como vimos, dichos mercaderes del interior fueron acusados por el Consulado de Burgos en 1547 por no respetar su exclusividad en el embarque de lana. La presencia de traficantes más o menos «exóticos» (sobre todo ingleses, algún italiano, andaluz o valenciano) no solamente se explica porque acudiesen en busca de hierro, sino también de las propias naves para el embarque de mercancías que, a veces, no tenían como destino o lugar de partida los puertos vascos.

No es éste lugar para el análisis de los negocios de los mercaderes individuales, las compañías comerciales, permanentes o puntuales, sus cargadores, encomenderos, consignatarios, factores, huéspedes, criados... que se desprenden de esta documentación, pero sí podemos adelantar algunos datos más extraídos de algunos de los contratos que nos informan al respecto, más allá de los nombres de los meros signatarios ${ }^{16}$.

La carta de flete 3. ${ }^{\text {a }}$ está suscrita, como muchas otras, por Luis Cruzad, en este caso en nombre del vitoriano Pedro Núñez de Alana y sus consortes. En ella se recogen las sacas de lana cargadas por Cruzad, tanto suyas como pertenecientes a otros tratantes, señaladas con sus marcas distintivas, indicándose los consignatarios a quienes debían ser entregadas en Flandes:

\footnotetext{
${ }^{16}$ Para un análisis sobre la figura de los factores, huéspedes y encomenderos, ANGULO MORALES, Alberto, «En poco tiempo vienen ricos e hacen a sus amos pobres». De factores o encomenderos a protagonistas directos del gran comercio internacional (siglos XV-XVII)", en Ernesto García Fernández (ed.), Bilbao, Vitoria y San Sebastián: espacios para mercaderes, clérigos y gobernantes en el Medievo y modernidad, Bilbao, Universidad del País Vasco, 2005, pp. 76-116. Para un repertorio bibliográfico actualizado sobre el comercio vasco del siglo XVI, BILBAO, Luis María y LANZA GARCíA, Ramón, op. cit.
} 
Tabla 3: Mercaderes y sacas de lana con sus marcas en el $3 . .9$ contrato de flete

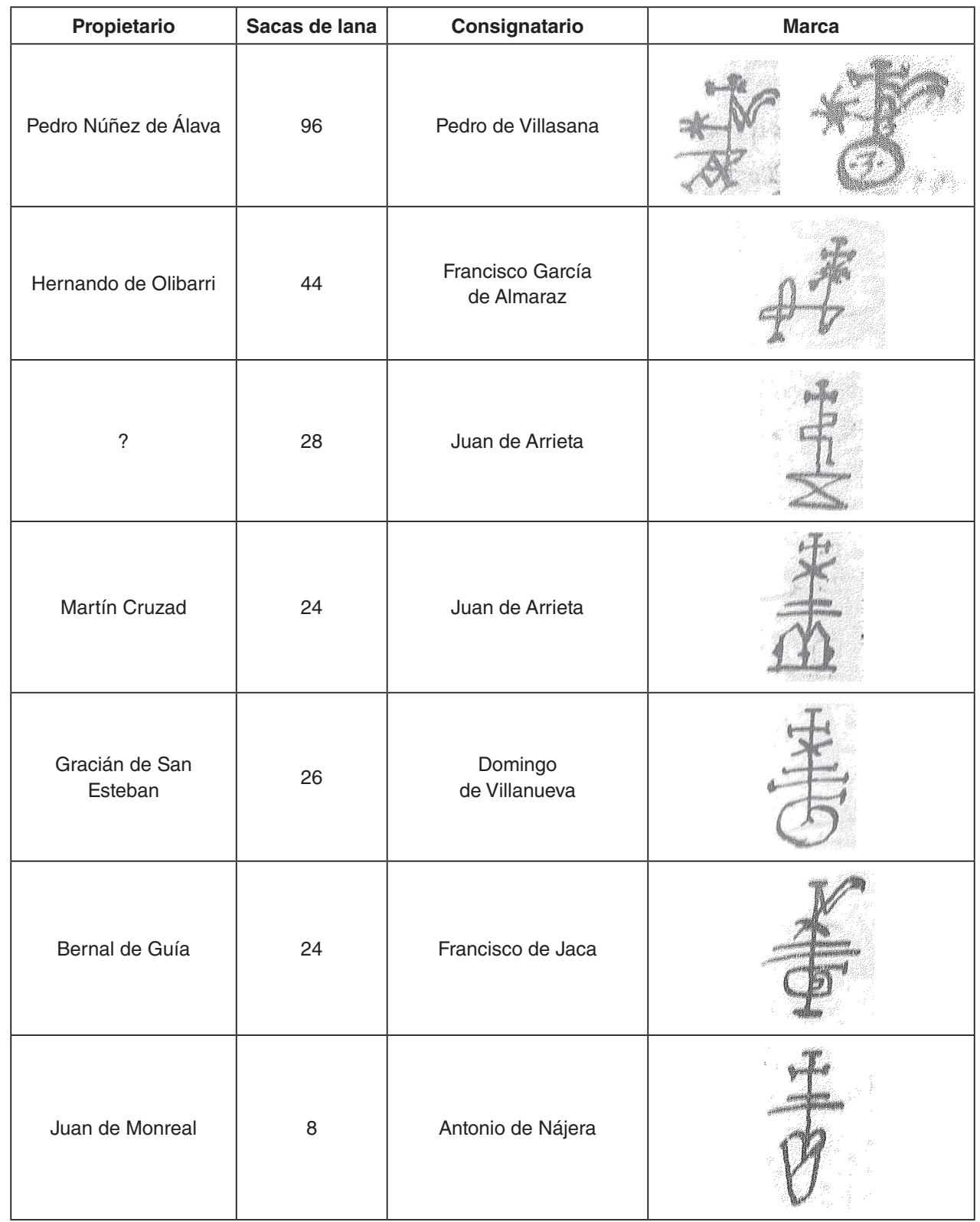


Transporte naval y envío de flotas comerciales hacia el norte de Europa...

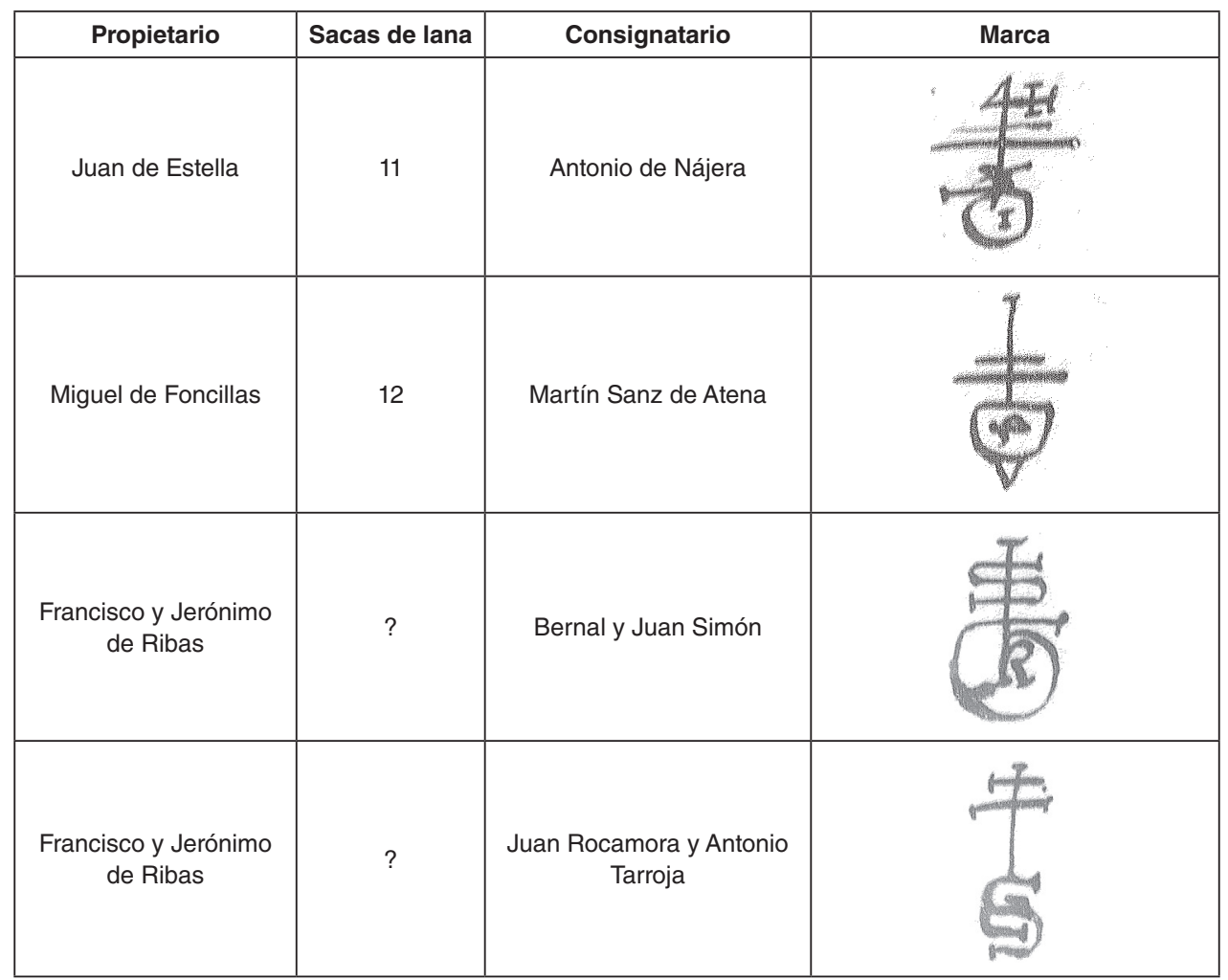

La carta situada en cuarto lugar es similar a la anterior, asimismo firmada por Cruzad; que también embarcó mercancías de otros comerciantes, junto a otro cargador, Martín Pérez de Barba, que fueron las siguientes:

Tabla 4: Mercaderes y mercancías con sus marcas en el $4 .^{\circ}$ contrato de flete

\begin{tabular}{|c|c|c|c|}
\hline Propietario & Mercancía & Consignatario & Marca \\
\hline Luis Cruzad & \multirow{2}{*}{100 sacas de lana } & Juan de Arrieta & \\
\hline Pedro Núñez de Álava & 80 sacas de lana & Pedro de Villasana & \\
\hline
\end{tabular}




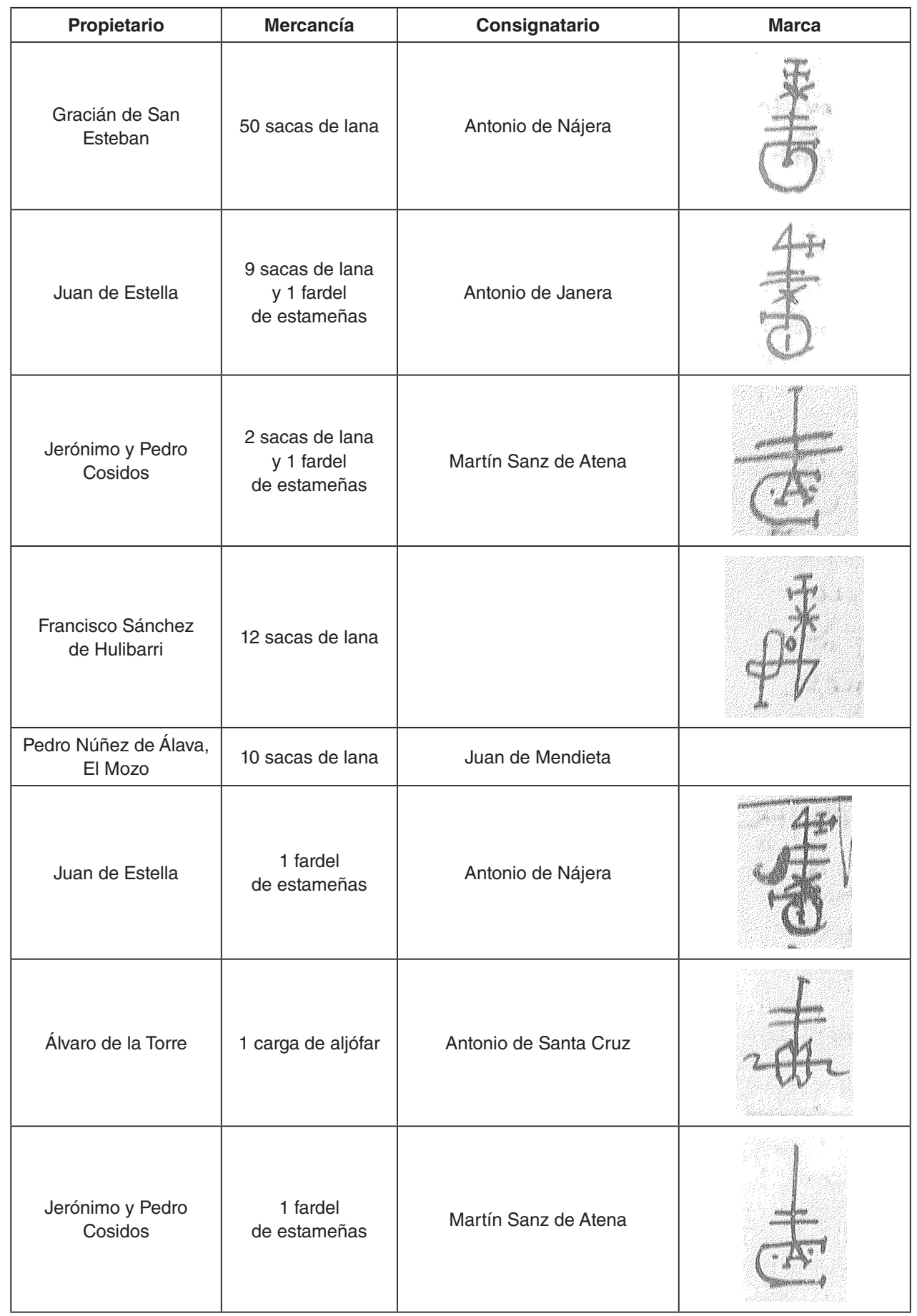


Transporte naval y envío de flotas comerciales hacia el norte de Europa...

\begin{tabular}{|c|c|c|c|}
\hline Propietario & Mercancía & Consignatario & Marca \\
\hline Luis Cruzad & $\begin{array}{c}17 \text { quintales con 18 } \\
\text { libras de hierro y } \\
53 \text { cabos }\end{array}$ & Juan de Arrieta & \\
\hline $\begin{array}{c}\text { Martín Pérez de Barba, } \\
\text { en nombre de Juan } \\
\text { Jiménez de Enciso } \\
\text { (vecino de Logroño) }\end{array}$ & 72 sacas de lana & $\begin{array}{c}\text { Rodrigo de Soria y Pedro } \\
\text { de Enciso }\end{array}$ & \\
\hline $\begin{array}{c}\text { Martín Pérez de Barba } \\
\text { en nombre Diego } \\
\text { Benito Díez }\end{array}$ & 8 sacas de lana & Rodrigo de Soria y Diego Benito & \\
\hline
\end{tabular}

En el quinto contrato de flete, aparte de Cruzad, otros cargadores fueron Juan de Aguirre y Juan de Zairra:

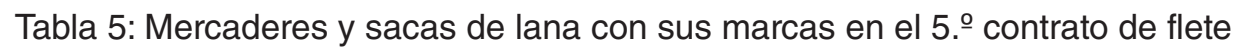

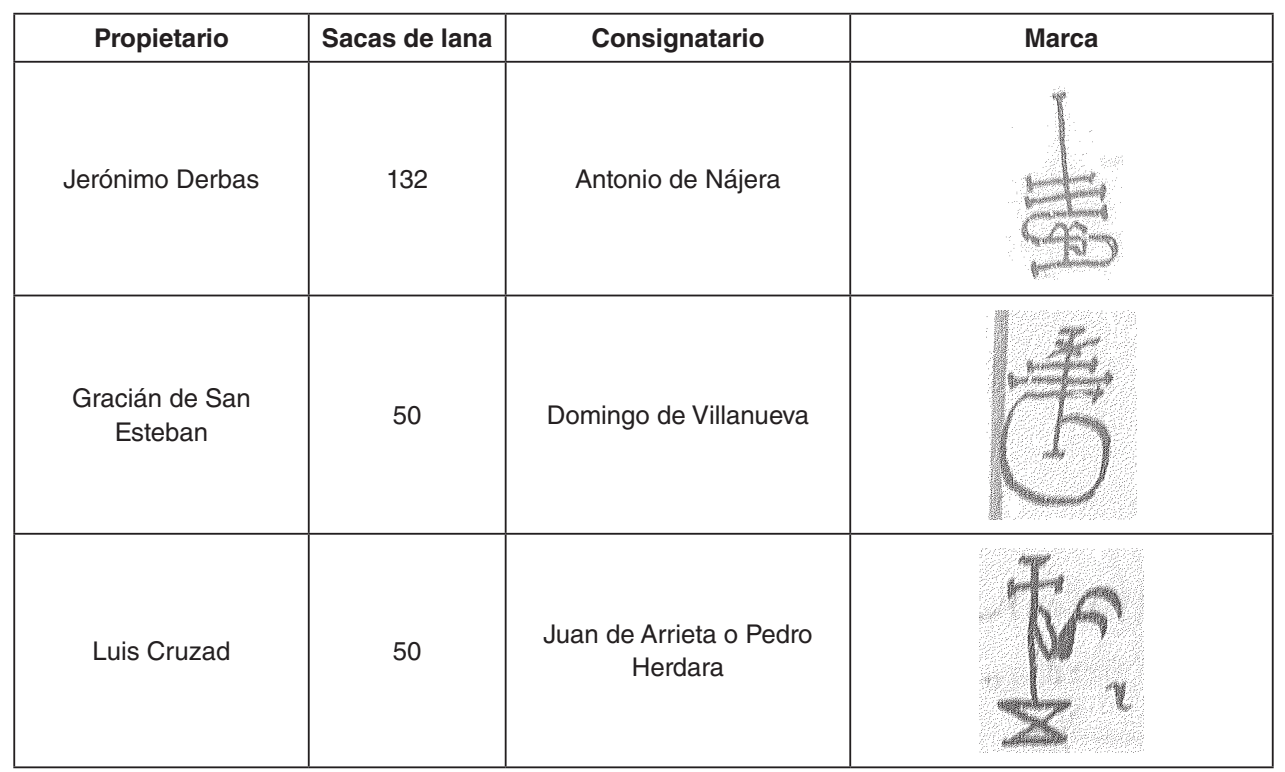




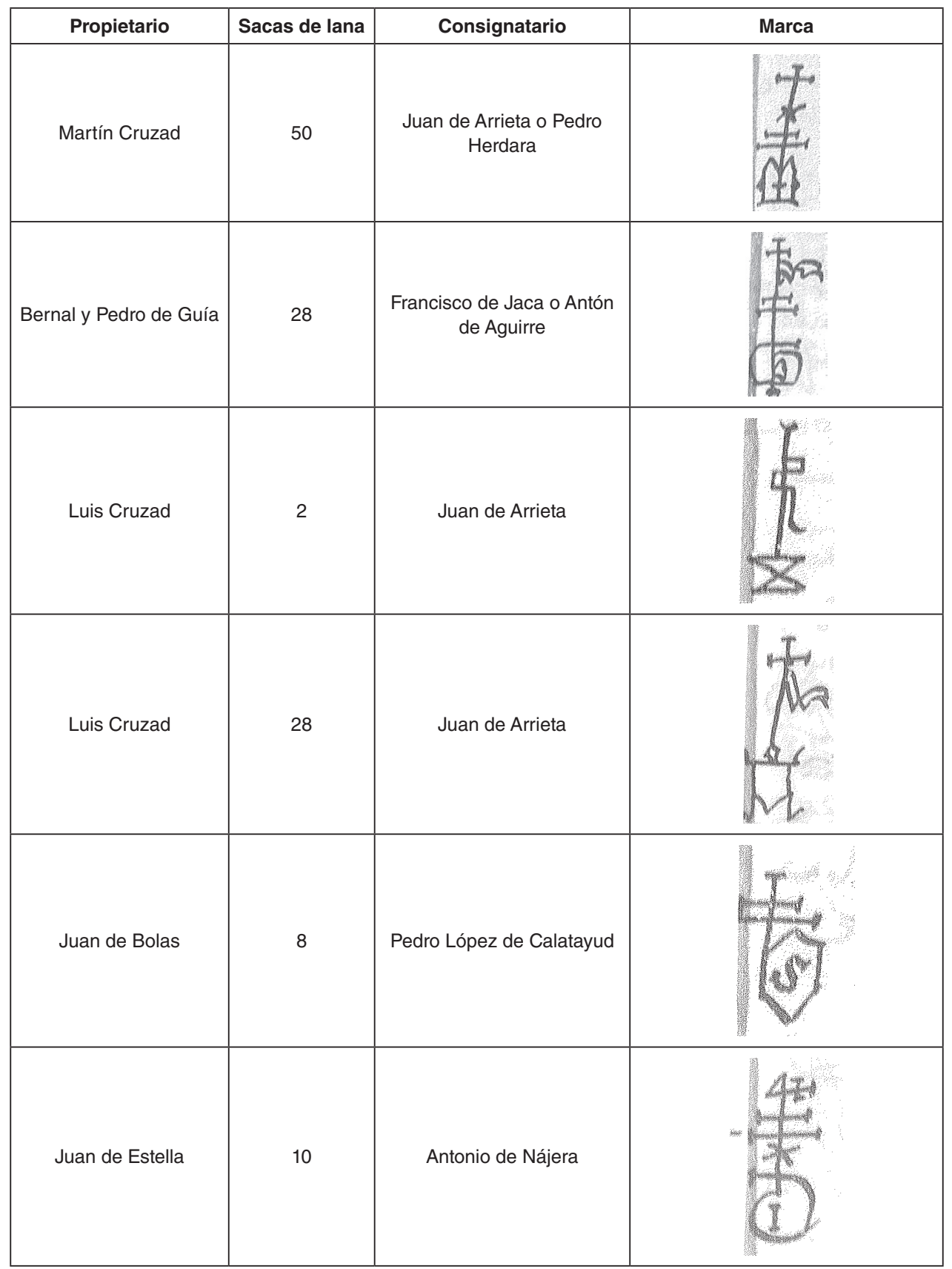


Transporte naval y envío de flotas comerciales hacia el norte de Europa...

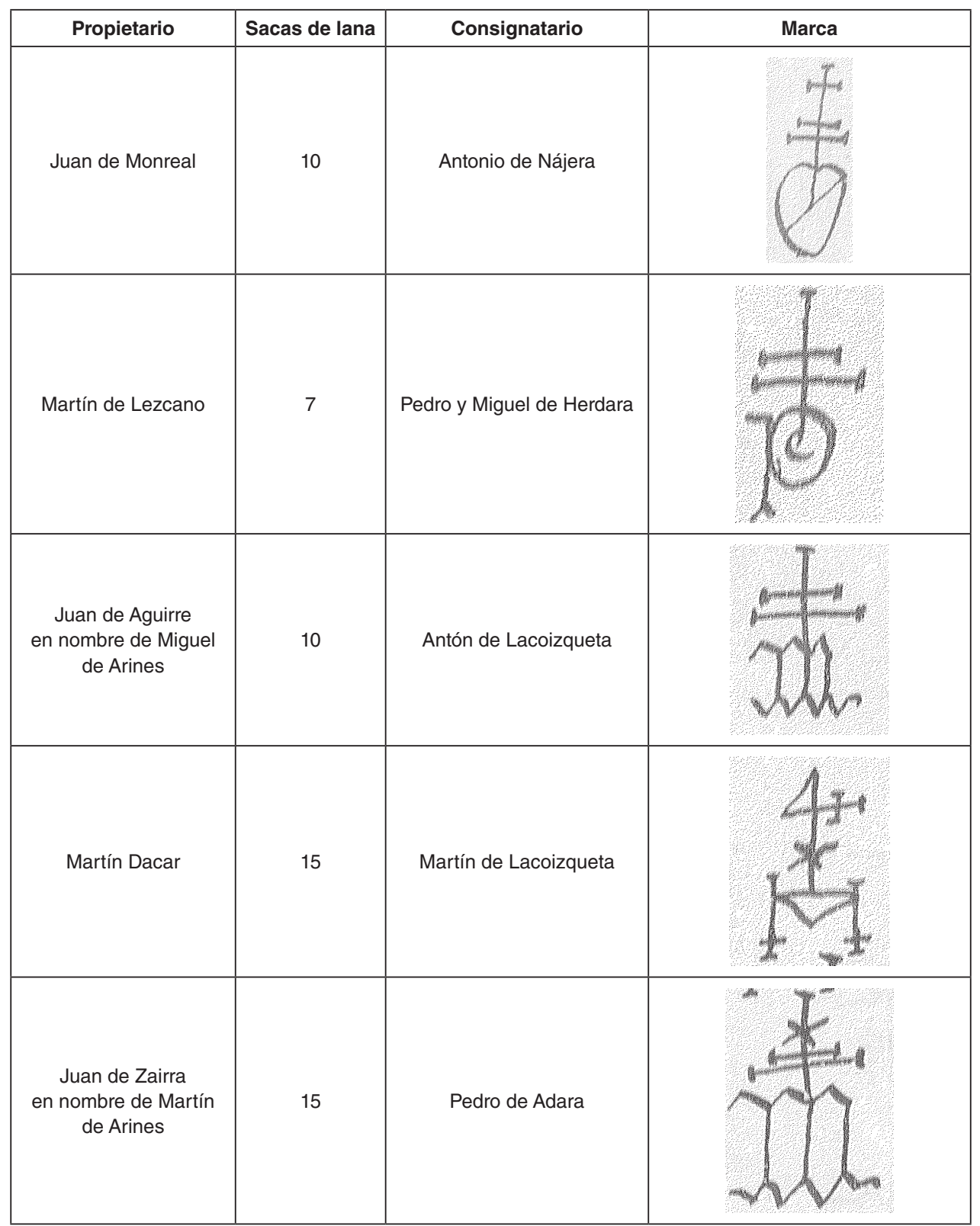


Y en el sexto, Cruzad y Martín Pérez de Barba:

Tabla 6: Mercaderes y sacas de lana con sus marcas en el $6 .^{\circ}$ contrato de flete

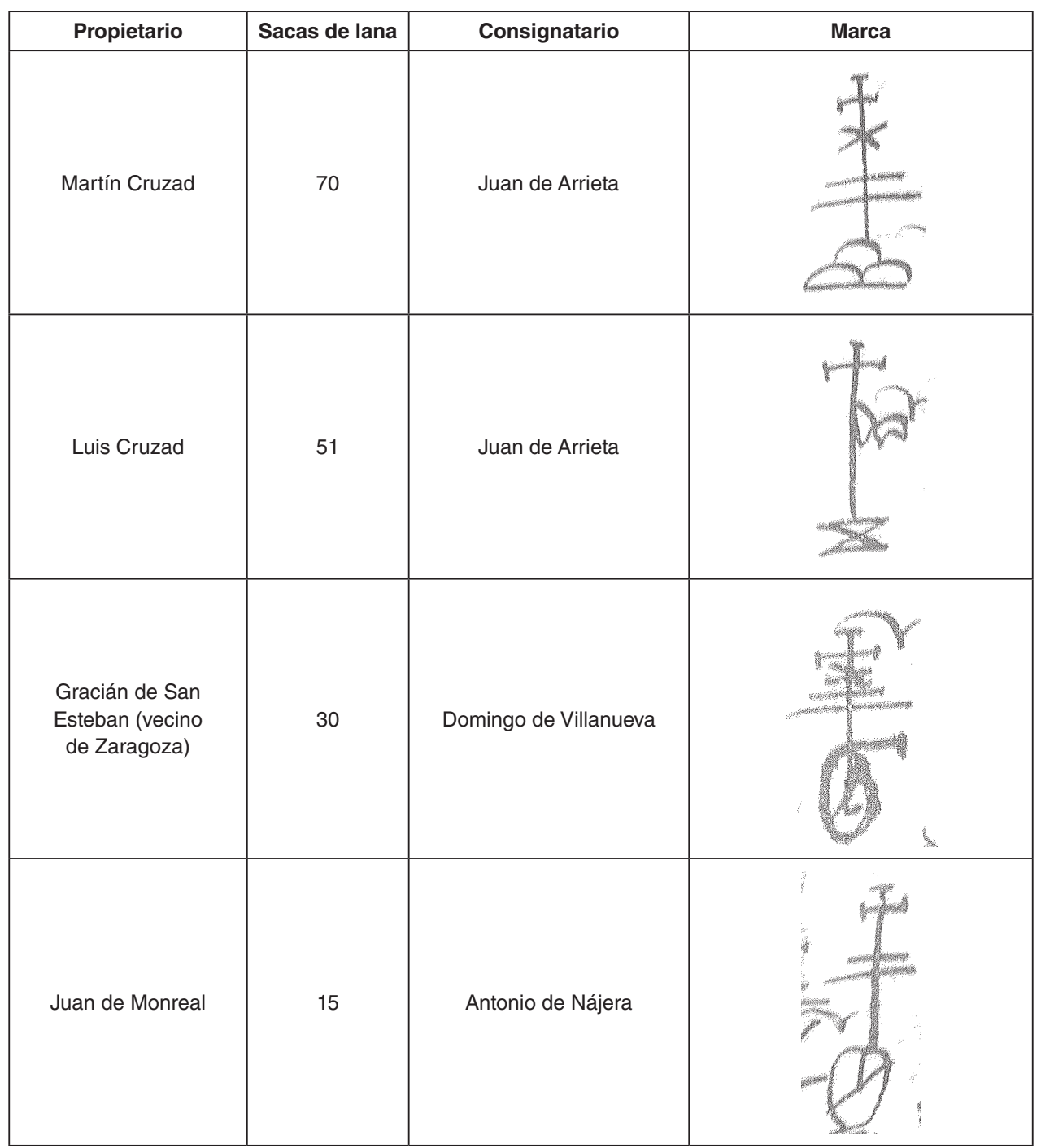


Transporte naval y envío de flotas comerciales hacia el norte de Europa...

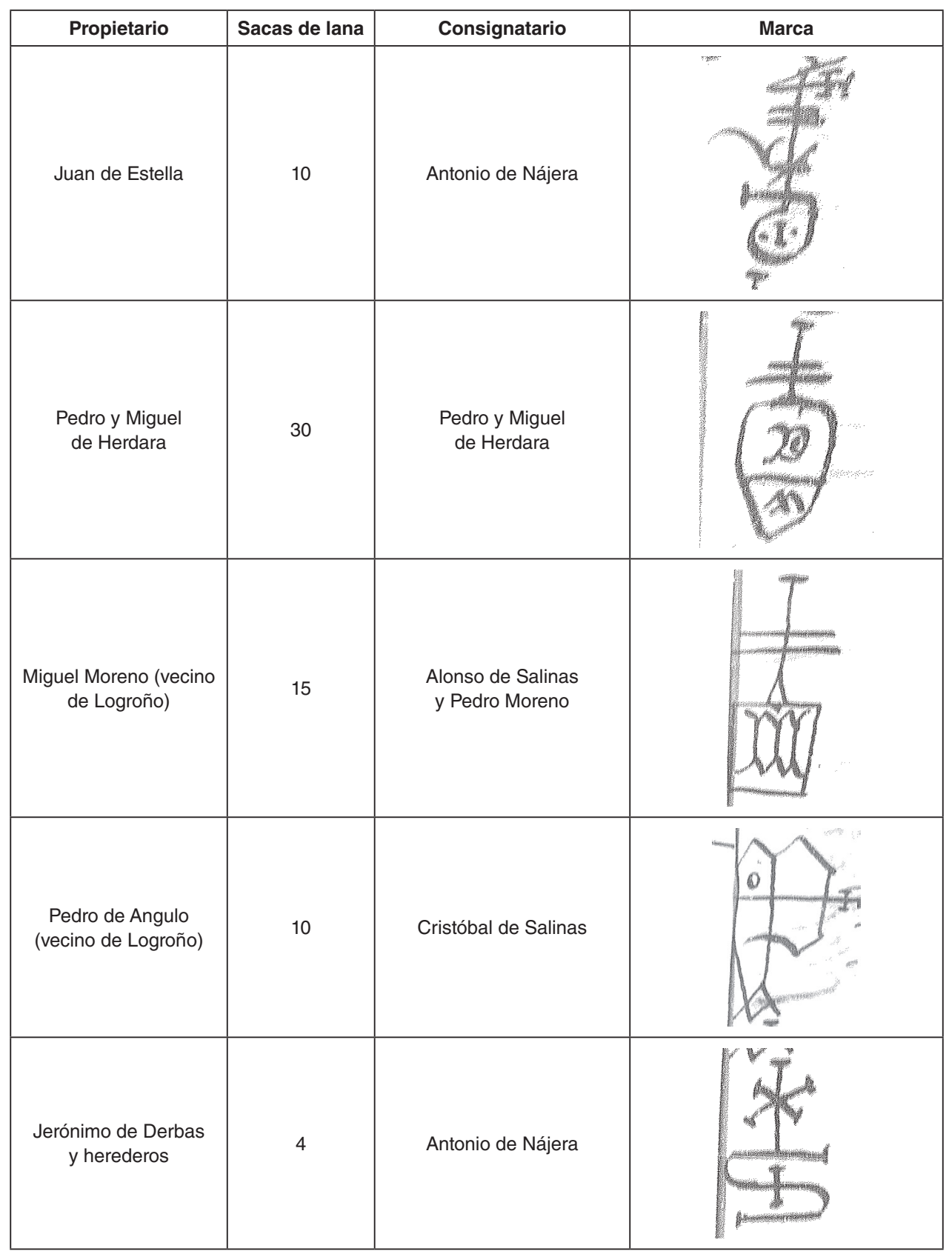




\begin{tabular}{|c|c|c|c|}
\hline Propietario & Sacas de lana & Consignatario & Marca \\
\hline $\begin{array}{c}\text { Jerónimo y Pedro } \\
\text { Cosidos }\end{array}$ & 2 & Martín Sanz de Tena & \\
\hline Juan de Huarte & 8 & Arnao del Plano & \\
\hline $\begin{array}{l}\text { Martín Pérez de Barba } \\
\text { en nombre de Juan } \\
\text { Jiménez de Enciso }\end{array}$ & 20 & $\begin{array}{c}\text { Pedro Fernández } \\
\text { y Francisco Fernández } \\
\text { de Navarrete }\end{array}$ & \\
\hline
\end{tabular}

En el séptimo documento, las 500 sacas de lana fueron cargadas por diferentes cargadores, y, aunque se hace mención a sus marcas, éstas, a diferencia de las cartas anteriores, no aparecen copiadas:

Tabla 7: Cargadores, mercaderes y sacas de lana en el 7.ำ contrato de flete

\begin{tabular}{|c|c|c|c|}
\hline Cargador & Propietario & Sacas & Consignatario \\
\hline \multirow{7}{*}{ Miguel de Yartua } & $\begin{array}{c}\text { Antonio y Diego de Yanguas } \\
\text { y Alonso Ruiz }\end{array}$ & 130 & $\begin{array}{l}\text { Hernando de Orozco } \\
\text { y Francisco de Sesma }\end{array}$ \\
\hline & $\begin{array}{c}\text { Juan Fernández de Navarrete } \\
\text { y Jerónimo Jiménez }\end{array}$ & 20 & Jerónimo Jiménez \\
\hline & Pedro Fernández de Navarrete & 10 & \multirow{2}{*}{ Hernando de Orozco } \\
\hline & Francisco de Tejada & 20 & \\
\hline & Juan de Montenegro & 30 & \\
\hline & $\begin{array}{c}\text { Juan de Deipa y Francisco } \\
\text { de Heali }\end{array}$ & 52 & Juan de Cuchu \\
\hline & Francisco de Echábarri & 36 & Francisco de Cuchu \\
\hline
\end{tabular}


Transporte naval y envío de flotas comerciales hacia el norte de Europa...

\begin{tabular}{|c|c|c|c|}
\hline Cargador & Propietario & Sacas & \multirow{2}{*}{ Consignatario } \\
\hline \multirow{3}{*}{ Miguel de Yartua } & Juan Ruiz de Gara & 18 & \multirow{2}{*}{} \\
\cline { 2 - 3 } & $\begin{array}{c}\text { Joana Pérez de Anda, Pedro } \\
\text { de Isunza y herederos de Pedro } \\
\text { de Olabe }\end{array}$ & 160 & \multirow{2}{*}{ Francisco y Antonio de Olabe } \\
\cline { 2 - 3 } & Pedro de Olabe & 4 & \\
\hline Antonio de Olabe & Gabriel Saporta, de Zaragoza & 10 & \multirow{2}{*}{ Juan de Matanza } \\
\hline Julián de Yanguas & Diego de Yanguas y cia. & 10 & \\
\hline
\end{tabular}

\subsection{Maestres y navíos}

Como en el caso de los mercaderes suscriptores de los contratos de flete, o fletantes, los fletadores, o dueños y maestres de las naves, más numerosos son los de San Sebastián (13), seguidos por los de Bilbao (8), Portugalete (7) y Deusto (6). Si bien los hay de casi todos los puertos vascos, no faltan tampoco algunos «exóticos», como bretones o gallegos, lo que indica que los comerciantes no siempre recurrieron a las embarcaciones locales.

Para encontrar información adicional a la contenida en la tabla del apéndice, y a modo de ejemplo de lo que se puede hallar este tipo de documentos, podemos recurrir, como en el caso anterior, a algunas de las actas más significativas. Como la 3. $\stackrel{a}{ }$, nuevamente. Suscrita por Jacobe de Sarobe, vecino de San Sebastián, y maestre de la nao La Magdalena, que Dios salue e guarde, que estaba atracada en el muelle de la villa, y el mercader Luis Cruzad, también vecino de San Sebastián (aunque a veces se lo cita como de Pamplona), con las siguientes condiciones: El maestre quedaba obligado a dar la nao franca de quilla, costados y gotera de tillados (suelo entablado), así como bien conzada y aparejada de aparejos, artillería, armazón, munición y gente armada. En ella debían embarcarse 400 sacas de lana, 300 bajo cubierta (bajo el tillado) determinadas por el mercader; por las cargadas en la cubierta, si sufriesen algún daño, debía responder el capitán, indemnizando a sus dueños. Las 400 sacas dadas por Cruzad podían ser suyas como de los otros mercaderes de Vitoria. Sin embargo, el maestre no debía embarcar otras algunas hasta haberse estibado las de Cruzad; generalmente los contratos solían ser excluyentes, de modo que no se podían llevar otras mercancías que no perteneciesen al fletante o sus socios, si bien algunos contemplan las que se permitía llevar a la tripulación, para hacer sus propios negocios. El fletador disponía de un plazo de 6 días, tras signarse la carta, para poner su nao a disposición del comerciante, debidamente aprestada, y partir con ella con el primer buen tiempo con rumbo a Flandes, a La Esclusa y no a Ramua; pero, si por temporal no pudiese arribar a aquélla, entonces sí podría atracar en la segunda, donde entregaría las sacas a las personas a las que iban consignadas, así como descontar las averías con los factores de los merca- 
deres vitorianos cargadores. Cruzad pagaría al comandante por las 400 sacas cuando arribase a puerto y se descargasen los fletes y averías 5 sueldos y 6 dineros de la moneda de Flandes por cada una, en un plazo máximo de 5 días tras echar el ancla. Luego del desembarco, el maestre debía hacerse de nuevo a la mar con el primer buen tiempo para emprender el retorno, yendo a embarcar trigo a Inglaterra, a los surgideros que Cruzad, o la persona que éste situase en la nave (encomendero), determinasen, desde Sandux (¿Southampton?) hasta el cabo de Porlan (¿Portsmouth?), en una cantidad de hasta 500 quarters, para que no se cargase en exceso, ubicados bajo el tillado; dar sebo para el granero del trigo; y, pagar las lemañaces. La mies debía ser entregada por el maestre en el fondeadero donde se acordase, en un plazo de 20 días, y se pagaría por flete el $20 \%$ de las fanegas transportadas. Para todo ello, los contrayentes obligaron sus personas y bienes materiales, comprometiéndose bajo pena de 200 ducados de oro para la otra parte.

En la carta que ocupa el séptimo lugar, tanto el escribano como el maestre de la nave son la misma persona. Sabíamos de escribanos dedicados al comercio, ahora vemos que también podían ser propietarios de navíos, pero no que éstos redactasen y registrasen los contratos en los que ellos mismos participaban. Aparte de las averías comunes, al maestre se le abonó un ducado que había gastado en limosnas y misas con las que pedir un buen viaje; otra parte de las averías fueron para el lemán que sacó el buque de la barra, otro ducado; para 3 pinazas con que arrastrarlo desde la misma, con 71 hombres en total, a razón de 1 real por cabeza; y 7 ducados de a 6 sueldos y 3 dineros por las costas que Antonio de Olabe tuvo en los 2 viajes que hizo al puerto a despachar el galeón, derechos del notario y otras costas, las cuales el maestre se obligó a abonar en Flandes a Francisco y Antonio de Olabe. Como había noticias de que ciertos barcos escoceses armados asaltaban las naves cargadas de ropas, se embarcaron 12 hombres «sobresalientes» pertrechados con arcabuces y ballestas, cuyo coste fue, por cada uno, de 13 coronas de a 6 sueldos de gruesos (moneda de Flandes). Para pagar estos «sobresalientes» y el resto de la avería gruesa debían contribuir todas las mercaderías que fuesen en el galeón.

En el contrato 57 se especifica que en caso de declararse guerra entre España y Francia, antes del embarque y partida de la mercancía, éste quedaría sin efecto y el viaje no tendría lugar. En el contrato 58 se dice que la nave contratada, que se encontraba en Portugalete, debía estar en 15 días en el puerto de San Sebastián, para cargar las 400 sacas de lana de Beroiz bajo su cubierta, que no se podían estibar con drao sino con tablas; así como otras 100 de Pedro de Isunza, vecino de Vitoria. Además, si Beroiz no quería transportar más sacas el fletador podía buscar a quien quisiese hacerlo en la localidad, con permiso de aquél. La embarcación debía partir con cualquier flota armada que estuviese lista para salir rumbo a Inglaterra. Beroiz también podía llevar personas de armas «sobresalientes», que podían disponer de espacio para cargar sus vituallas y retornar en 
esa nave o en otra de su elección. Si salían otros navíos de San Sebastián o Deva, el barco había de partir en su compañía, pero si el fletante quería que lo hiciese desde Laredo con la flota conjunta, el fletador debía cumplirlo. Lo de la armada para Inglaterra o la partida conjunta, y lo de los «sobresalientes» se repite en otros contratos posteriores, como el 59; por su parte en el 60 se reitera lo de la partida conjunta, con las flotas de Inglaterra, Laredo o con las otras embarcaciones contratadas por Beroiz, mientras que en los «sobresalientes» debía también contribuir el fletador.

En la carta 65 el galeón con rumbo a Flandes debía partir con las sacas de lana desde Pasajes; como algunos de los mercaderes fletantes tenían esta materia prima en San Sebastián, el maestre fletador tenía que correr con el coste de transportarla en pinazas hasta el puerto de embarque, más una encomienda (dinero para pagar al encomendero) de $14 \mathrm{mrs}$. por saca; si éstas llegaban desde otras partes diferentes a San Sebastián el maestre sólo correría con la encomienda y los mercaderes con el coste del traslado. Cargadas las lanas, el capitán debía partir junto con otras naves que saliesen del puerto de Deva o de la propia Pasajes, o ir en solitario si así lo decidían los fletantes; que podían incluir, si lo estimaban, la protección de los «sobresalientes».

El contrato 66 consta de una carta de poder que el dueño y maestre de la nao La Concepción, Martín de Ortiz de Orozco, firmó en favor de Martín de Villa, vecino de Portugalete, de Juan de Ugarte, escribano de la nave, y de Juan de Leusarra, contramaestre de la misma, ambos de Deusto, para que en su nombre, cualquiera de ellos, la pudiese dar en flete; algo que debió de ser bastante habitual cuando no eran los propios dueños los que suscribían las cartas de fletamento, pero que en estos contratos no se habría recogido para evitar alargar innecesariamente las pruebas aportadas en el pleito. El barco fue en primer lugar fletado por el propietario a Juan de Bazán, vecino de Logroño, y a Pedro de Isunza, de Vitoria, para que llevasen en él 800 sacas de lana desde Bilbao a Flandes, según acuerdo suscrito en Logroño, ante el escribano Lope de Villoslada. El maestre trasladó la embarcación luego a Pasajes y arguyó que los fletantes le darían allí la lana, la cual reclamó a los comerciantes Julián de Yanguas y Miguel de Beroiz, que supuestamente debían entregarla en nombre de los susodichos. Sin embargo, éstos alegaron que no tenían lanas algunas de los mismos, aunque se comprometieron, junto con Esteban Cruzad y Domingo de Iraeta, a cargar las 800 sacas de sus propias lanas, según las condiciones de flete del contrato original, aunque abonando más por saca. Este fletamento se hacía junto a otros que previamente habían acordado con Sancho de la Quadra y Jesús de Aguirre. Martín de Ortiz debía afrontar los gastos del desplazamiento de las lanas desde Fuenterrabía, San Sebastián y Rentería a Pasajes, desde donde saldría su nave con ellas rumbo a Flandes, así como 14mrs. de encomienda por saca, aunque de las de Fuenterrabía abonaría solamente $6 \mathrm{mrs} . / \mathrm{saca}$, y el resto, los due- 
ños. La partida se haría con las otras naos fletadas o en solitario, según decidiesen los mercaderes.

En el contrato 67 se dispone que la nave San Pedro, del maestre Francisco Illarreta, debía salir rumbo a Flandes en solitario, en compañía de las de los mercaderes bilbaínos Juan Martínez de Gorri y Francisco de Trento, que se encontraban en Pasajes, o junto a otras que el mercader fletante, Miguel Beroiz, le indicase. El fletador debía abonar 14mrs. por saca de lana en concepto de encomienda, más otros 3 para la carga de cada una. También, entregarle una lista con los nombres de los marineros, grumetes, pajes y «sobresalientes» (para los que se estipulan condiciones similares a las más arriba vistas), así como de las piezas de artillería, pólvora, munición y armamento de mano que llevase; idénticas relaciones había de darlas en Flandes, tras la arribada, para que se pudiese comprobar cómo se había cumplido el acuerdo.

En el último, el 68, se incluye una cláusula mediante la cual se exoneraba al mercader cargador de las sacas de lana de intervenir en el pleito que se pudiese derivar del hecho de que otro maestre exigiese su mercancía para llevarla en su barco; sin duda en función de la preferencia de embarque para los navíos de mayor tonelaje, que más arriba hemos visto, de modo que solamente el primer capitán contratado debía interponer dicho pleito si lo estimaba conveniente. Asimismo, se repite lo de la compañía de otras naves, la contratación de «sobresalientes» y la redacción de listados de tripulantes y armamento.

Algunos acuerdos especifican el tipo de embarcaciones de las que se trataba (22 carabelas, 20 naos, 18 galeones y 1 pinaza); y, a veces, su tonelaje (204 toneles la mayor y 80 la menor, de las 6 en las que aparece). También el puerto en el que se encontraban ancladas en el momento de la firma y la tripulación que iban a llevar; en cuyo caso se distingue entre marineros, grumetes, pajes y hombres de armas. También el armamento de esta tripulación, armas de fuego y ballestas, así como el de la nave; diferenciándose entre las piezas gruesas, como las bombardas, y los versos. Otros aspectos que se podían recoger eran el de la munición o las características de los castillos de proa o popa donde iba ésta o el armamento. Algo en lo que aquí no podemos profundizar.

\subsection{Mercancías y destinos}

La principal mercancía contenida en los contratos de flete es el hierro/acero; aparece en 32 de ellos (47\%), de los que en 18 es la única transportada. Del mismo se especifica, en ocasiones, cómo viajaba: en astillas, flejes de astería, flejes de picos, bergajón, cabos, hojas, barriles... Se embarcó, preferentemente, en San Sebastián (10 barcos) y Pasajes (7), puerto cuya jurisdicción compartía 
la primera villa con Fuenterrabía; le siguen de cerca Bilbao (9) y Ondárroa (4) ${ }^{17}$. Su destino mayoritario fueron las islas Británicas (19 barcos), sobre todo Londres (10) y Bristol (3), así como algunos otros surgideros no identificados por haber sido transcritos fonéticamente. El resto de destinos es muy variado, con apenas un par de embarcaciones los más frecuentados. Con estos documentos, los miembros del Consulado de Bilbao quisieron argumentar que durante los primeros 50 años del siglo XVI el mayor volumen del tráfico comercial realizado al margen del de Burgos se centró en el hierro, lo que no contravenía, pues, las ordenanzas acordadas con él, que dejaban a cargo de Bilbao la organización del flete de esta materia prima.

Tras el hierro, la lana es el siguiente artículo de importancia por el número de embarcaciones en las que aparece, 26, en 21 de forma exclusiva. Ya hemos visto cómo viajaba en sacas, en ocasiones pertenecientes a un solo mercader fletante, pero frecuentemente propiedad de varios de ellos, asociados de forma permanente o temporal para el fletamento, en cuyo caso iban debidamente rotuladas con la marca de cada uno. El principal amarradero de salida fue, de nuevo, San Sebastián, al que se menciona en 14 ocasiones, seguido de su sucursal, Pasajes (5), y otros dos Guipuzcoanos, Deva (5) y Fuenterrabía (1). El destino fue, casi en solitario, Flandes, los embarcaderos de Ramua y La Esclusa, citados ambos en 18 ocasiones. Es de señalar la ausencia de fondeaderos vizcaínos para el embarque de esta materia prima, lo que vendría a suponer que el Consulado de Bilbao descargaba sobre los comerciantes y puertos guipuzcoanos la responsabilidad de la trasgresión de las ordenanzas que garantizaban el fletamento exclusivo a Bur$\operatorname{gos}^{18}$. En ese mismo sentido, no hay contratos de lana anteriores a 1525, fecha próxima a 1533, cuando expiraba el tratado que respaldaba la vigencia de las citadas ordenanzas; de modo que, de nuevo, Bilbao trataba de demostrar que no lo había transgredido del todo, y que fue a partir de dicha fecha cuando empezó a caer en desuso y a darse la exportación libre de esta mercancía, eso sí, por puertos guipuzcoanos. Y en barcos de pequeño tonelaje, con unas 400 sacas, o menos, cada uno, muy por debajo de los vistos en el fletamento general de 1547; lo que estaba en sintonía con la excepción contenida en las ordenanzas que permitía a pequeños navíos llevar algo de lana a las costas francesas para traer subsistencias como mercancía de retorno.

Junto a estas materias primas destacan otros artículos comerciales de exportación por los puertos vascos, como el vino (citado en 8 ocasiones), el pastel (3) y los paños (2). Mientras que los retornos, presentes en 15 contratos, casi siempre consistieron en cereal, paños, cueros o plomo. A este respecto el contrato núme-

\footnotetext{
17 No obstante, el principal puerto exportador de hierro durante el siglo XVI fue Bilbao (BILBAO, Luis María y LANZA GARCÍA, Ramón, op. cit., 117).

${ }_{18}$ Al contrario que ocurrió con el hierro, Bilbao no fue en el XVI un importante puerto lanero, como Santander, o el propio Bilbao en el XVII (Ídem, 117). En parte, sin duda, por el boicot del Consulado de Burgos, como más arriba hemos visto.
} 
ro 47 contiene gran variedad de artículos y destinos. Aparte del fletante principal, Miguel de Beroiz, figura uno secundario, Martín de Goizueta, ambos vecinos de San Sebastián. Lugar de partida de La Bárbara, donde el primero embarcó el bacalao y las sacas de lana; 24 de ellas de la marca de Miguel Foncellas, las otras 16 de la marca de Miguel Gea, ambos vecinos de Zaragoza; para ser entregadas a Mateo de Foncellas, estante en La Rochela, surgidero de destino. Por su parte, el segundo contrayente embarcó el hierro, labrado en las herrerías del Urumea, en 413 cabos; tanto éste como el pescado debían ser dados a Pierre Arnaot, vecino de La Rochela.

\section{CONCLUSIÓN}

La exhumación de nueva documentación desconocida nos está permitiendo en los últimos años acercarnos a una mejor noción de las características del comercio peninsular con el norte de Europa a través de los puertos vascos durante la primera mitad del siglo XVI. Momento trascendental para la historia de España por haber alcanzado durante el mismo su mayor apogeo de tiempos modernos, pero mal estudiado por la carencia de fuentes primarias para este elemento esencial de la actividad económica, debido a la destrucción sufrida por los archivos locales.

Sin embargo, gracias a que parte de los documentos originales fueron trasladados a pleitos y otras fuentes conservadas en los archivos generales, como la Chancillería de Valladolid o Simancas, podemos ir aproximándonos a un análisis de detalle sobre cómo se articuló el intercambio mercantil con Europa, más allá de las informaciones impresionistas que nos habían aportado hasta ahora los datos indirectos.

Este es el caso que aquí traemos, el estudio de 68 cartas particulares de flete y de dos contratos generales de la flota de Flandes, únicos en su género para este período, que nos han permitido corroborar aspectos ya sabidos, como la rivalidad comercial entre Burgos y Bilbao, y cómo se aplicó la legislación que regulaba el tráfico con Europa. Pero, sobre todo, nos aportan una valiosa información de primera mano, hasta ahora solamente intuida, sobre la redacción y cláusulas de tales documentos, los escribanos que los escrituraron o cómo fueron traspasados a otros. Los tipos de barcos empleados, el tonelaje, aparejos, velamen, tripulación y armamento, el lugar donde se ubicaba la carga, etc. Quiénes fueron los propietarios de dichos buques, quiénes sus maestres, su origen, sus vínculos familiares o su lugar de actividad. Los puertos de embarque y de reembarque o partida, los de arribada y las escalas por el camino, las rutas seguidas en los trayectos de ida y en los retornos, los viajes en solitario, en pequeñas flotillas o las grandes armadas conjuntas. Las mercancías con las que se traficó y en las fechas en las que se hizo, variedad, cantidad, procedencia y destino. Los 
Transporte naval y envío de flotas comerciales hacia el norte de Europa...

propietarios de dichas mercancías, sus socios, las compañías comerciales, los empleados, factores, consignatarios, su origen, su lugar de residencia, los vínculos que los unían... 


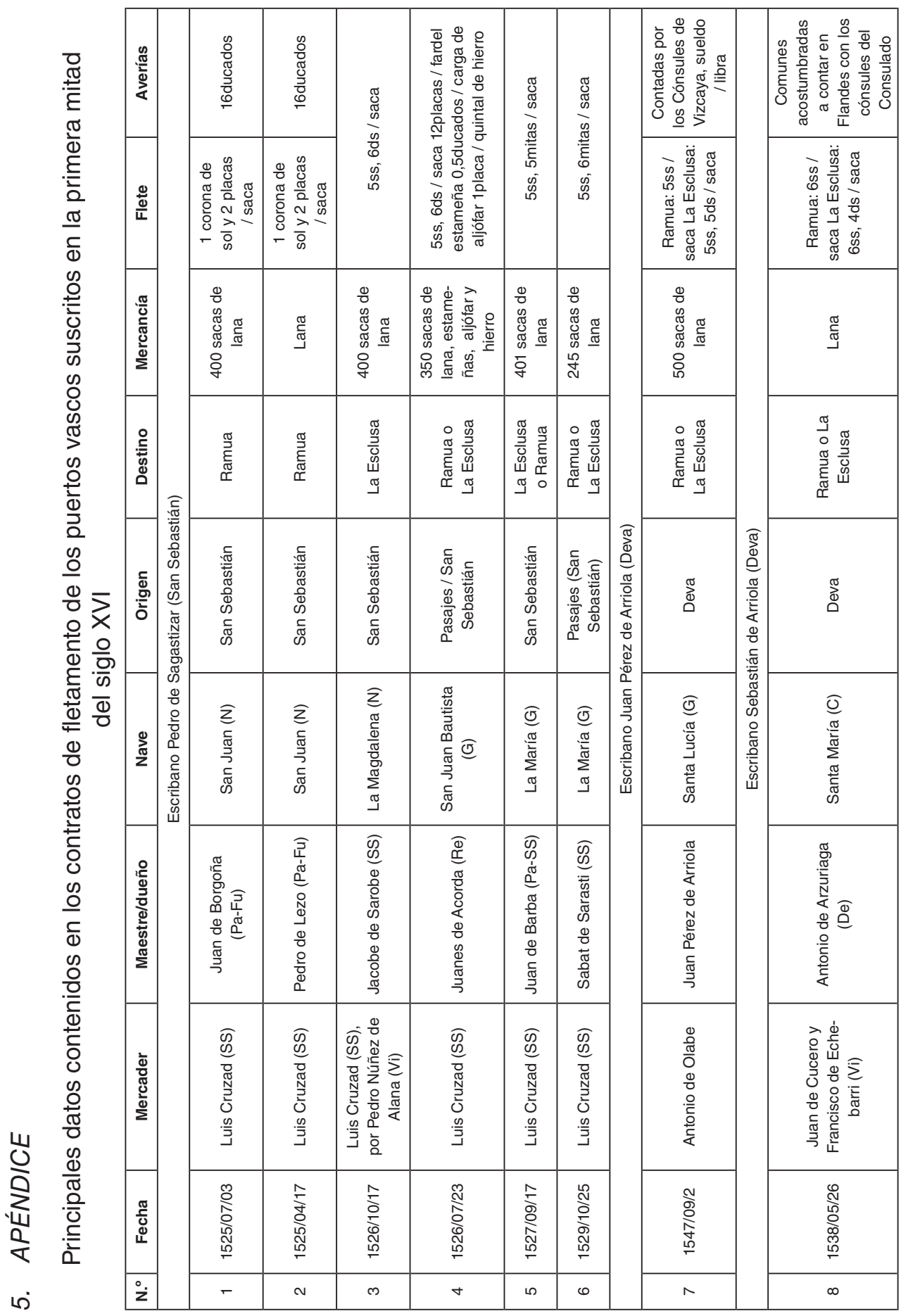


Transporte naval y envío de flotas comerciales hacia el norte de Europa...

\begin{tabular}{|c|c|c|c|c|c|c|c|c|c|c|c|c|c|}
\hline 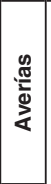 & & 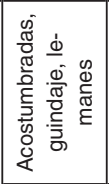 & 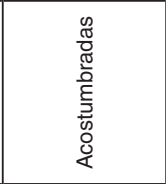 & & 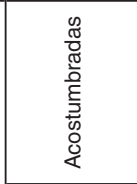 & $\begin{array}{l}\circ \\
\text { 응 } \\
0 \\
0 \\
0 \\
0\end{array}$ & & 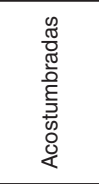 & & 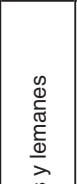 & $\begin{array}{l}\mathscr{w} \\
\stackrel{\tilde{w}}{\tilde{E}} \\
\frac{\tilde{E}}{\lambda}\end{array}$ & & 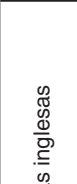 \\
\hline$\frac{\frac{\Phi}{L}}{4}$ & & $\begin{array}{l}\text { D } \\
\text { N } \\
\text { co } \\
0 \\
n\end{array}$ & 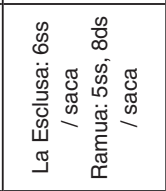 & & 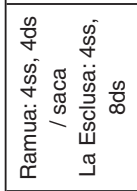 & 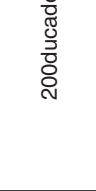 & & 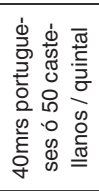 & & 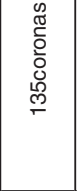 & 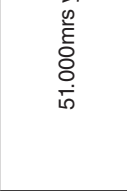 & & 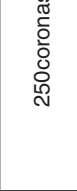 \\
\hline 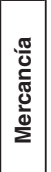 & & 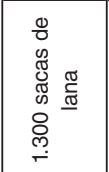 & 丞 & & 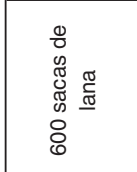 & $\begin{array}{l}\stackrel{\circ}{\mathbb{U}} \\
\stackrel{4}{4}\end{array}$ & & 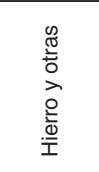 & & 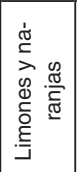 & & & $\begin{array}{l}\frac{O}{\underline{\underline{\theta}}} \\
\frac{\stackrel{\underline{T}}{I}}{2}\end{array}$ \\
\hline 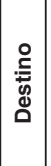 & & 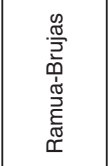 & 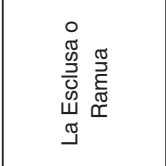 & & 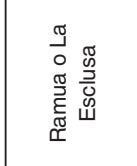 & 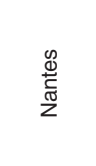 & 0 & 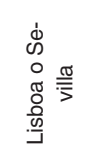 & 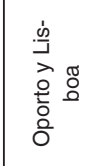 & 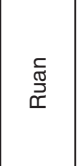 & 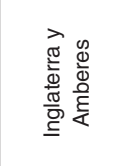 & $\begin{array}{l}\widehat{\mathcal{O}} \\
\stackrel{0}{=}\end{array}$ & $\begin{array}{l}\mathscr{\mathscr { \omega }} \\
\frac{\mathscr{\omega}}{\overline{0}} \\
\bar{\sigma}\end{array}$ \\
\hline 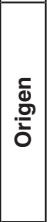 & 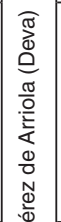 & ه్ & ס्ञ & 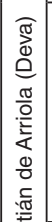 & هั & هั & 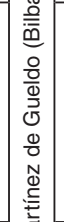 & $\begin{array}{l}\stackrel{̊}{\circ} \\
\text { 帝 }\end{array}$ & 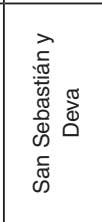 & 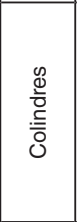 & 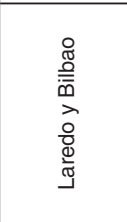 & 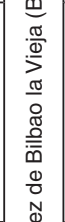 & 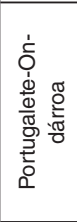 \\
\hline $\begin{array}{l}0 \\
\text { II } \\
\text { II }\end{array}$ & 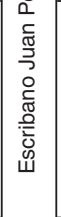 & 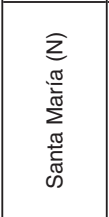 & 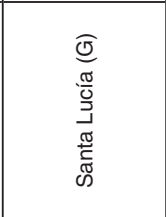 & 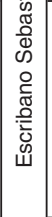 & 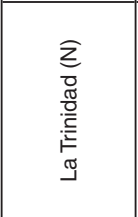 & 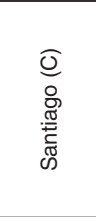 & 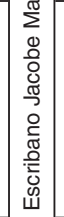 & 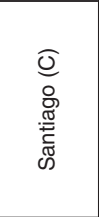 & 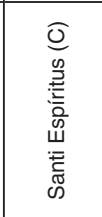 & 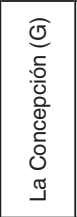 & 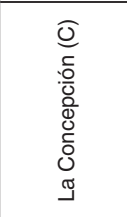 & 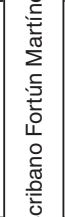 & 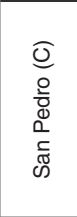 \\
\hline 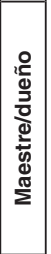 & & 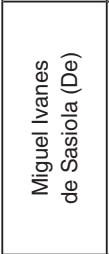 & 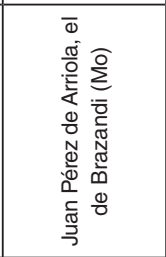 & & 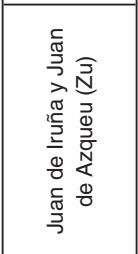 & 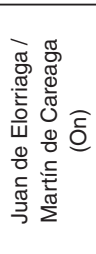 & & 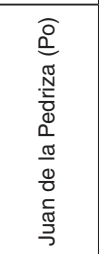 & 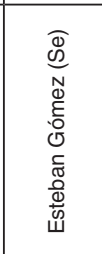 & 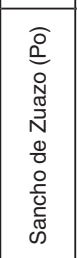 & 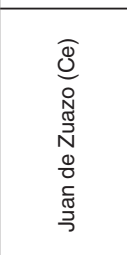 & 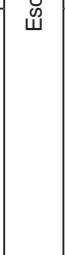 & 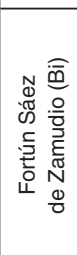 \\
\hline 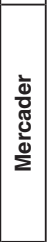 & & 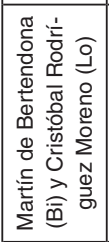 & 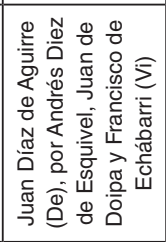 & & 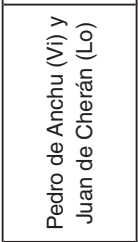 & 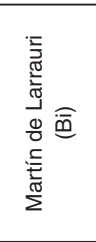 & & 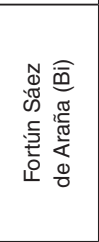 & 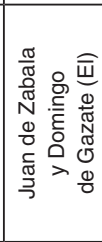 & 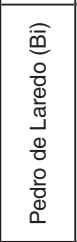 & 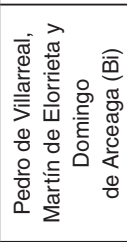 & & 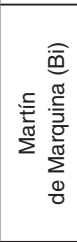 \\
\hline 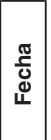 & & $\begin{array}{l}\bar{N} \\
\infty \\
\stackrel{0}{0} \\
\stackrel{0}{0} \\
\stackrel{1}{c}\end{array}$ & 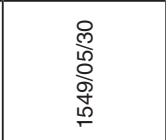 & & 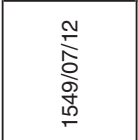 & $\begin{array}{l}\stackrel{N}{7} \\
\frac{1}{2} \\
\stackrel{N}{N} \\
\stackrel{N}{\Gamma}\end{array}$ & & 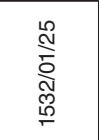 & 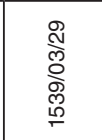 & $\begin{array}{l}\stackrel{m}{2} \\
\frac{0}{5} \\
\frac{1}{0} \\
\frac{10}{2}\end{array}$ & 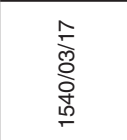 & & $\begin{array}{l}\frac{m}{N} \\
\frac{0}{0} \\
\frac{0}{0} \\
\frac{1}{r}\end{array}$ \\
\hline$\dot{z}$ & & 0 & 으 & & $F$ & $\simeq$ & & $\stackrel{m}{\longrightarrow}$ & $\underset{+}{ \pm}$ & $\stackrel{\circ}{\circ}$ & $\stackrel{\varphi}{\circ}$ & & 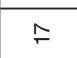 \\
\hline
\end{tabular}




\begin{tabular}{|c|c|c|c|c|c|c|c|c|}
\hline 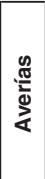 & & 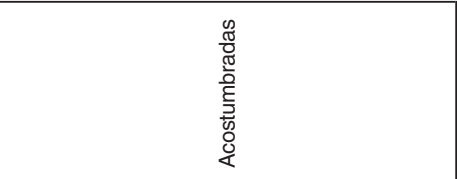 & 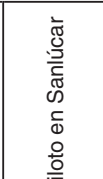 & $\begin{array}{l}\mathbb{8} \\
\mathbb{D} \\
\frac{\mathscr{E}}{\Phi} \\
\stackrel{\Xi}{\subseteq}\end{array}$ & 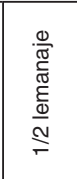 & 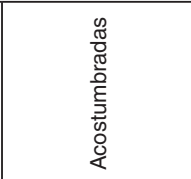 & 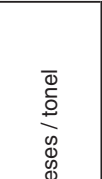 & \\
\hline$\frac{\frac{\Phi}{L}}{4}$ & 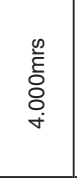 & 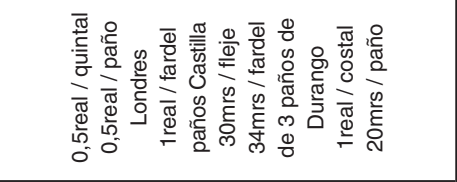 & 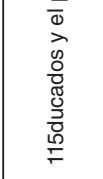 & 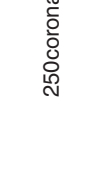 & 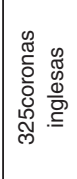 & 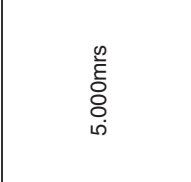 & $\begin{array}{l}.9 \\
. \\
0 \\
0 \\
0 \\
\infty \\
\infty\end{array}$ & \\
\hline 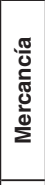 & $\begin{array}{l}\frac{\pi}{\frac{\pi}{0}} \\
\frac{\pi}{2} \\
\frac{\pi}{2}\end{array}$ & 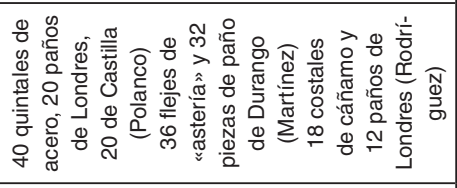 & 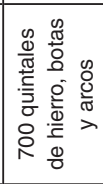 & 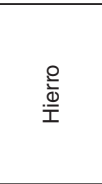 & 总 & 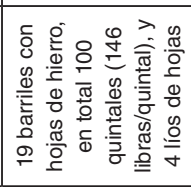 & 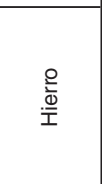 & \\
\hline 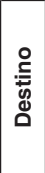 & 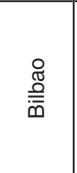 & 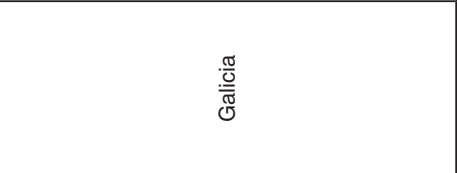 & 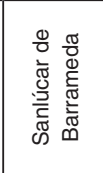 & 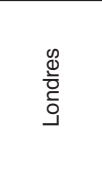 & 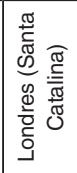 & 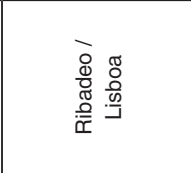 & 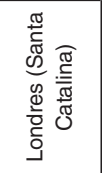 & \\
\hline 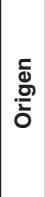 & 离 & & 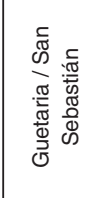 & 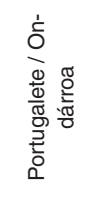 & 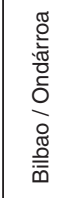 & 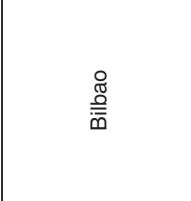 & 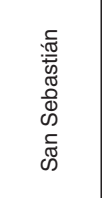 & \\
\hline 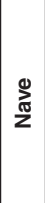 & 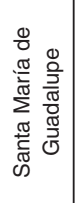 & 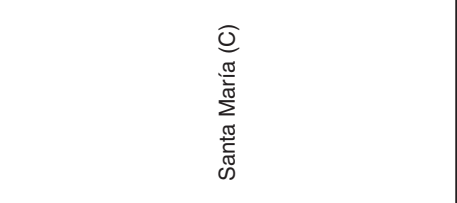 & 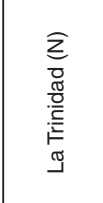 & 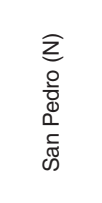 & 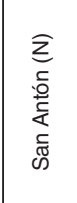 & 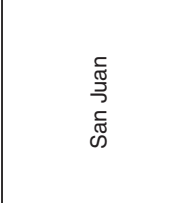 & 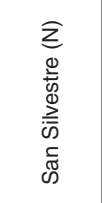 & 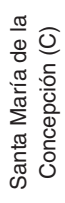 \\
\hline 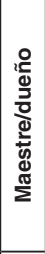 & 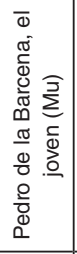 & 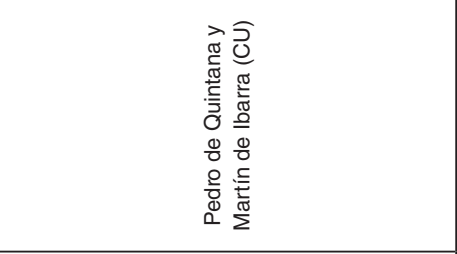 & 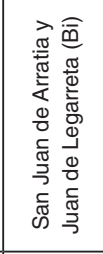 & 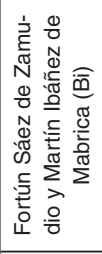 & 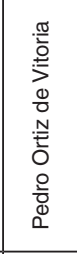 & 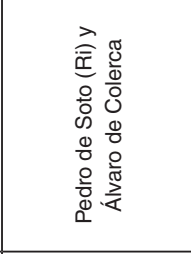 & 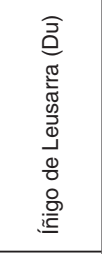 & 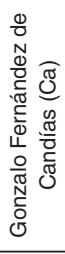 \\
\hline 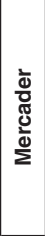 & 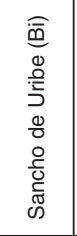 & 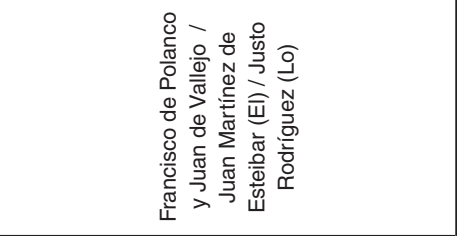 & 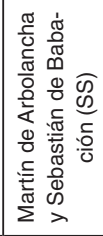 & 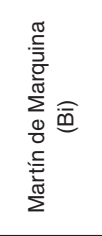 & 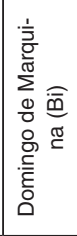 & 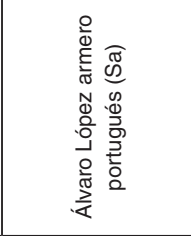 & 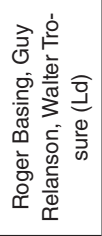 & 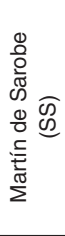 \\
\hline 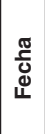 & 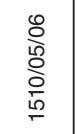 & 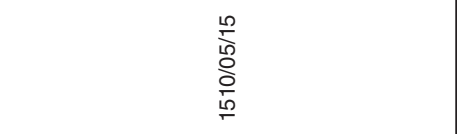 & $\begin{array}{l}\text { 이 } \\
\text { 잉 } \\
\text { 임 } \\
\stackrel{10}{r}\end{array}$ & $\begin{array}{l}\stackrel{ }{N} \\
\stackrel{\circ}{\circ} \\
\frac{0}{0} \\
\stackrel{10}{r}\end{array}$ & $\frac{\stackrel{N}{N}}{\stackrel{N}{N}}$ & $\begin{array}{l}\frac{0}{2} \\
\frac{1}{0} \\
\frac{7}{5}\end{array}$ & 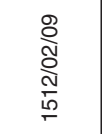 & 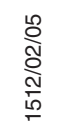 \\
\hline$\stackrel{\circ}{z}$ & $\stackrel{\infty}{\leftarrow}$ & $\stackrel{9}{\circ}$ & ㅇ & $\bar{\Lambda}$ & N & $\stackrel{\text { N }}{ }$ & $\stackrel{d}{\sim}$ & $\stackrel{\llcorner}{\mathrm{N}}$ \\
\hline
\end{tabular}


Transporte naval y envío de flotas comerciales hacia el norte de Europa...

\begin{tabular}{|c|c|c|c|c|c|c|c|c|c|}
\hline 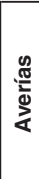 & 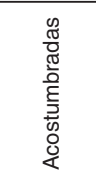 & 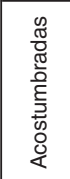 & 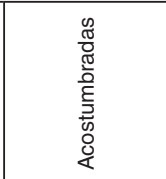 & 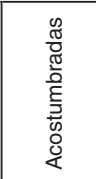 & 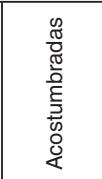 & 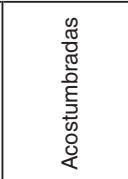 & 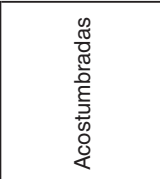 & 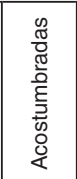 & 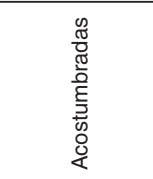 \\
\hline$\frac{\Phi}{\frac{\omega}{L}}$ & 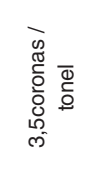 & 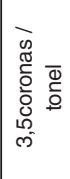 & 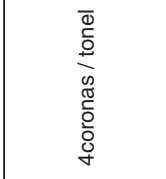 & 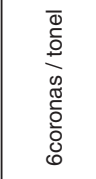 & 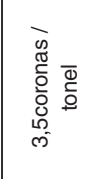 & 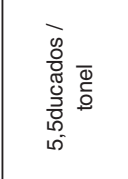 & 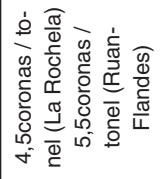 & 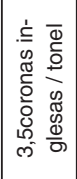 & 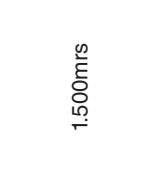 \\
\hline 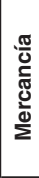 & 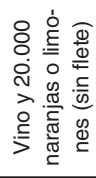 & 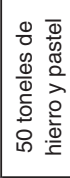 & 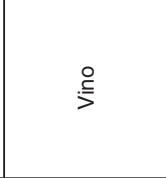 & 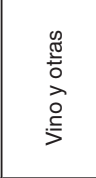 & 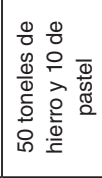 & 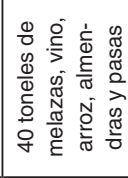 & 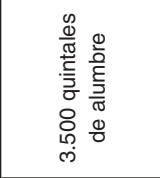 & 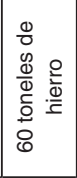 & 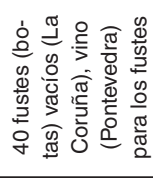 \\
\hline 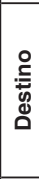 & 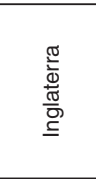 & 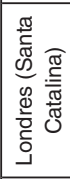 & 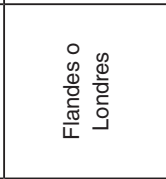 & 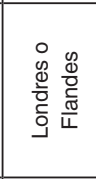 & 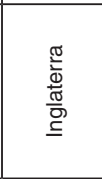 & 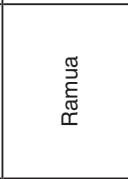 & 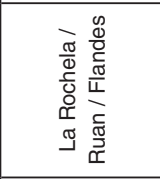 & 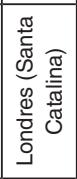 & 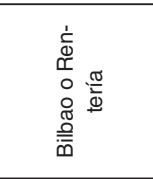 \\
\hline 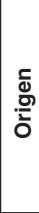 & 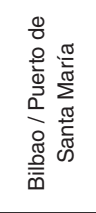 & $\begin{array}{l}\stackrel{8}{\approx} \\
\text { 总 }\end{array}$ & 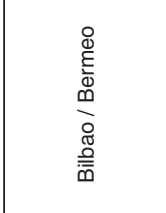 & 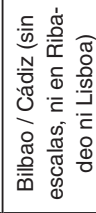 & & 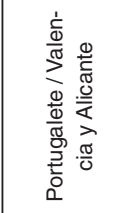 & 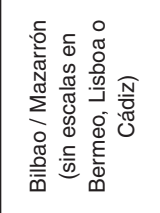 & 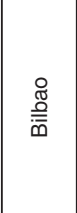 & 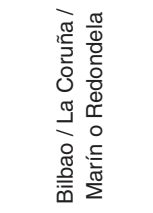 \\
\hline $\begin{array}{l}\stackrel{0}{\text { IJ }} \\
\text { L }\end{array}$ & 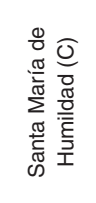 & 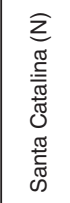 & 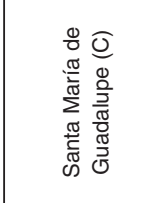 & 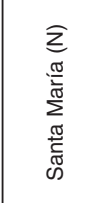 & 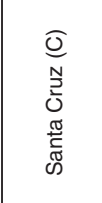 & 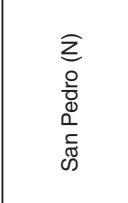 & 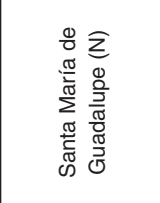 & 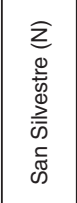 & 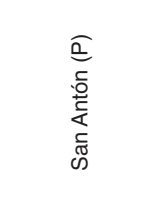 \\
\hline 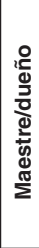 & 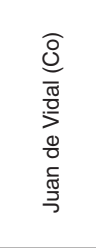 & 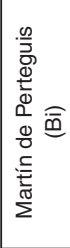 & 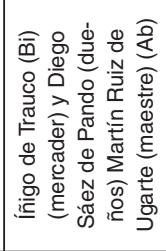 & 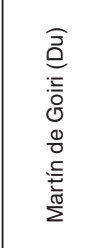 & 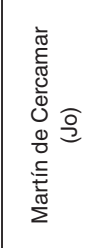 & 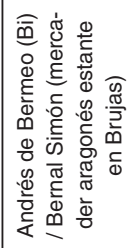 & 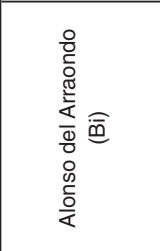 & 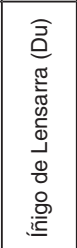 & 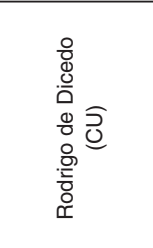 \\
\hline 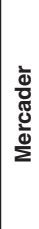 & 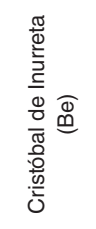 & 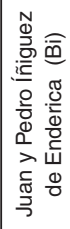 & 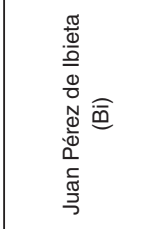 & 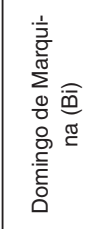 & 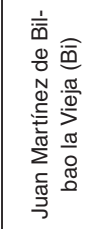 & 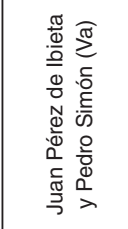 & 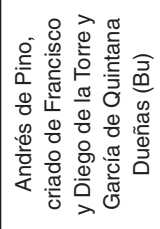 & 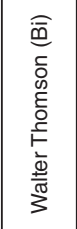 & 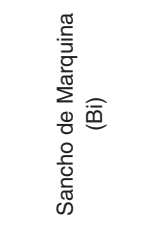 \\
\hline \begin{tabular}{|l}
$\frac{\pi}{0}$ \\
这
\end{tabular} & 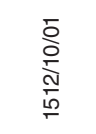 & 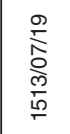 & $\begin{array}{l}\stackrel{\stackrel{N}{N}}{\circ} \\
\frac{0}{0} \\
\frac{0}{5}\end{array}$ & $\frac{\substack{0 \\
\frac{1}{0}}}{\frac{0}{20}}$ & 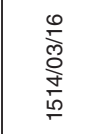 & 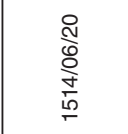 & 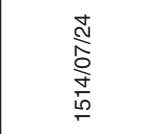 & $\begin{array}{l}\stackrel{\infty}{N} \\
\frac{0}{5} \\
\frac{0}{0} \\
\frac{10}{n}\end{array}$ & $\frac{\sqrt{6}}{\frac{5}{5}}$ \\
\hline$\stackrel{\circ}{z}$ & $\stackrel{\leftrightarrow}{N}$ & $\hat{N}$ & $\stackrel{\infty}{\sim}$ & న & ి) & ल & ల్ల & ల్ల & ले \\
\hline
\end{tabular}




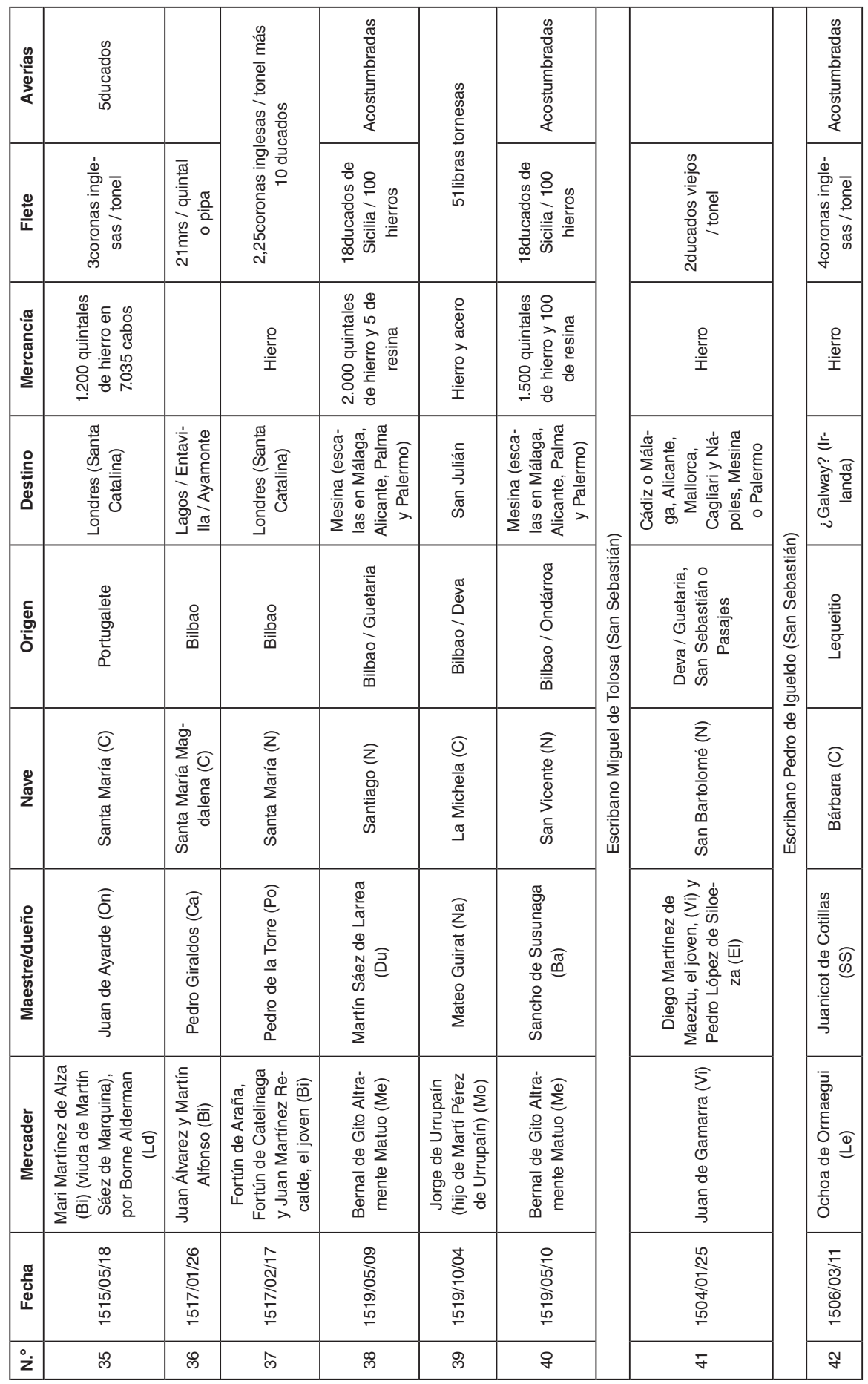


Transporte naval y envío de flotas comerciales hacia el norte de Europa...

\begin{tabular}{|c|c|c|c|c|c|c|c|c|c|c|c|}
\hline 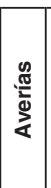 & & 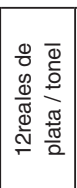 & 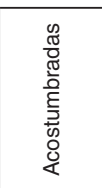 & 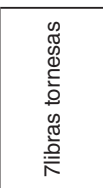 & 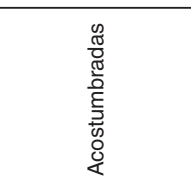 & 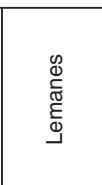 & 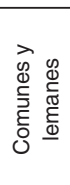 & & 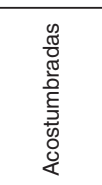 & 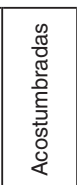 & 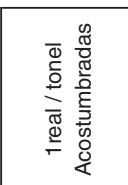 \\
\hline$\frac{\Phi}{\frac{\Phi}{L}}$ & 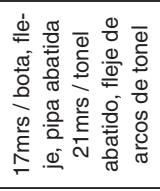 & 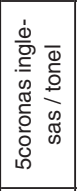 & 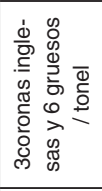 & 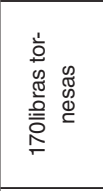 & 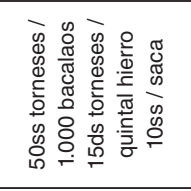 & 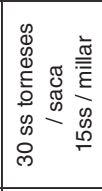 & 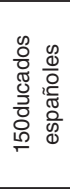 & & 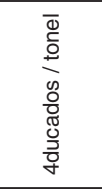 & 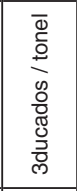 & 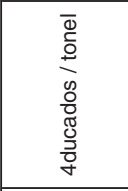 \\
\hline 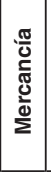 & 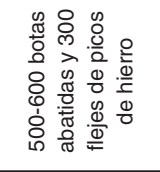 & 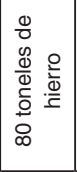 & 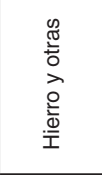 & 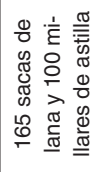 & 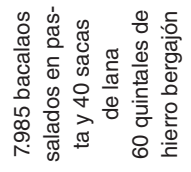 & 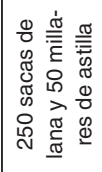 & 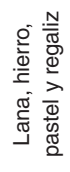 & & 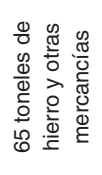 & 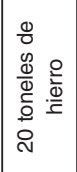 & 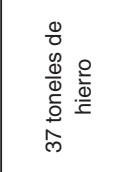 \\
\hline 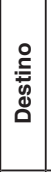 & 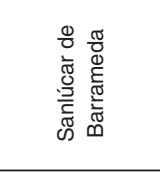 & 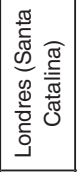 & 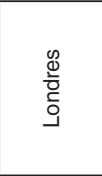 & 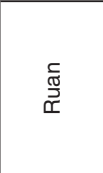 & $\begin{array}{l}\frac{\pi}{0} \\
\frac{0}{0} \\
\frac{0}{0} \\
\Xi \\
\unlhd\end{array}$ & 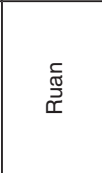 & 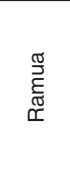 & 䔅 & 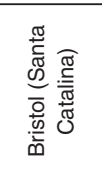 & $\begin{array}{l}\overline{\mathrm{o}} \\
\frac{5}{\bar{m}} \\
\overline{\mathrm{D}}\end{array}$ & 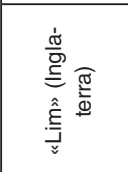 \\
\hline $\begin{array}{l}\bar{\Xi} \\
\stackrel{\varpi}{\Xi} \\
\overline{0}\end{array}$ & & $\begin{array}{l}\mathscr{0} \\
\stackrel{\mathscr{J}}{\mathbb{D}} \\
\mathbb{0} \\
0\end{array}$ & 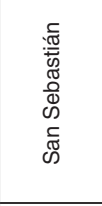 & 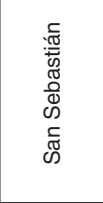 & 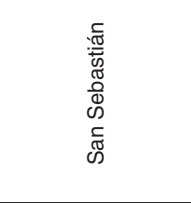 & 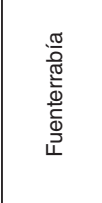 & 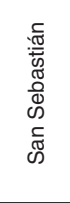 & 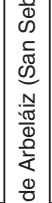 & 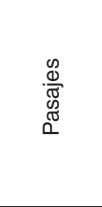 & 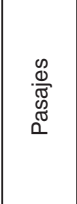 & $\begin{array}{l}\mathscr{0} \\
\mathbb{\pi} \\
\mathbb{D} \\
\widetilde{0} \\
0\end{array}$ \\
\hline $\begin{array}{l}0 \\
\text { II } \\
\text { I }\end{array}$ & $\frac{\frac{\pi}{\pi}}{\frac{\pi}{20}}$ & 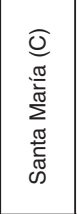 & $\begin{array}{l}\widehat{0} \\
\frac{0}{0} \\
\frac{\pi}{0} \\
\frac{0}{z}\end{array}$ & 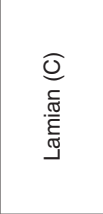 & 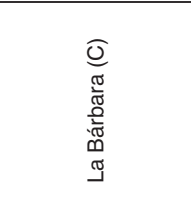 & 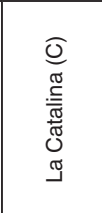 & 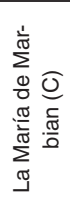 & 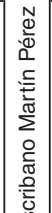 & 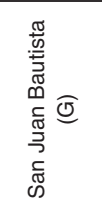 & 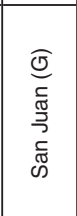 & 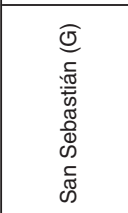 \\
\hline 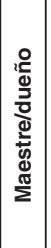 & 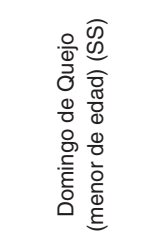 & 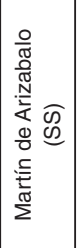 & 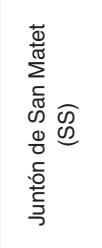 & 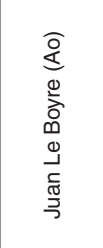 & 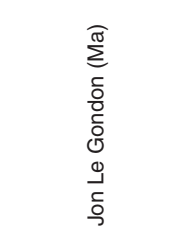 & 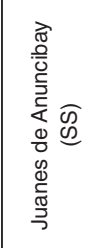 & 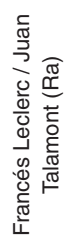 & & 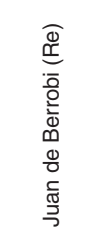 & 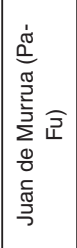 & 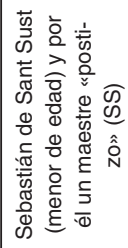 \\
\hline 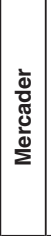 & 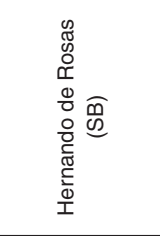 & 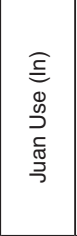 & 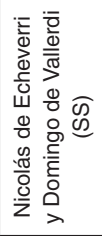 & 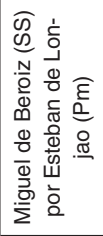 & 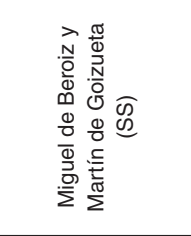 & 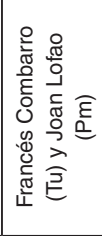 & 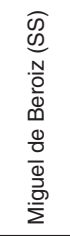 & & 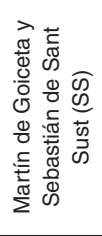 & 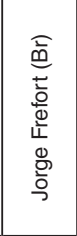 & 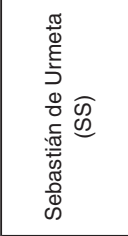 \\
\hline 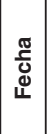 & 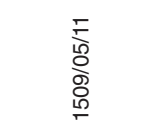 & 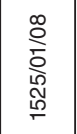 & 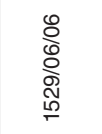 & 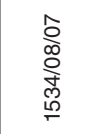 & 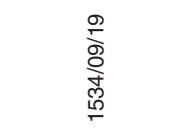 & 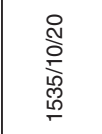 & 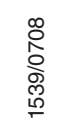 & & 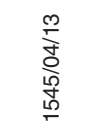 & 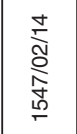 & 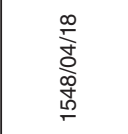 \\
\hline $\mathfrak{z}_{\mathbf{z}}$ & $\mathscr{8}$ & J & $\stackrel{\text { \& }}{f}$ & g & $\hat{f}$ & $\stackrel{\infty}{+}$ & \& & & in & is & กิ \\
\hline
\end{tabular}




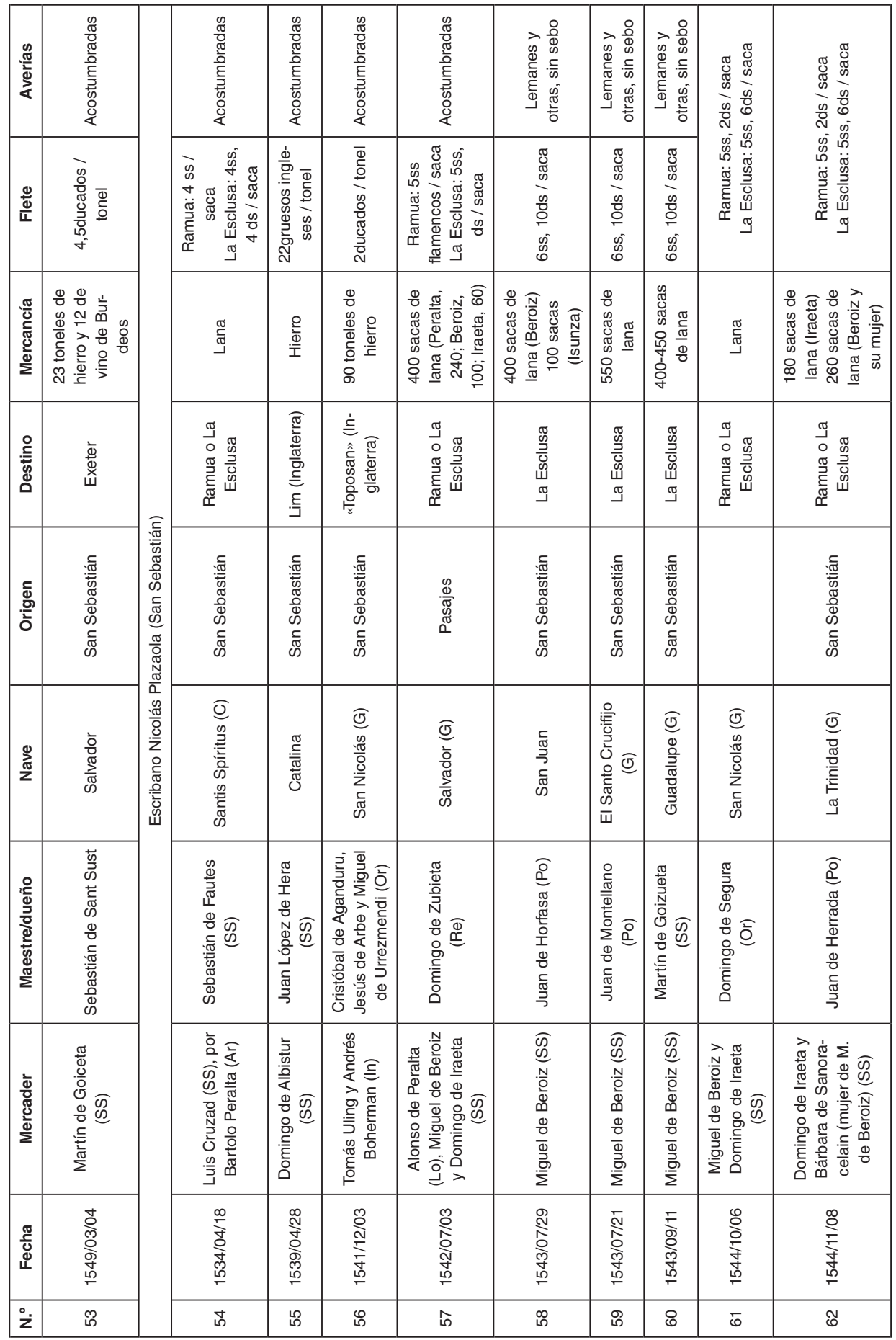


Transporte naval y envío de flotas comerciales hacia el norte de Europa...

\begin{tabular}{|c|c|c|c|c|c|c|}
\hline 恋 & 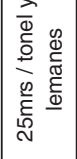 & 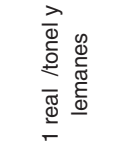 & \multirow{2}{*}{ 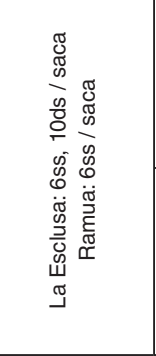 } & 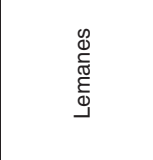 & & \\
\hline$\frac{\mathrm{d}}{\underline{\mathrm{\omega}}}$ & 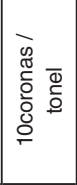 & 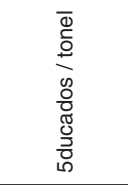 & & 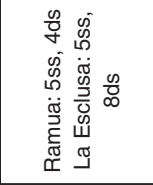 & 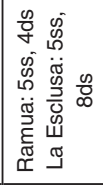 & 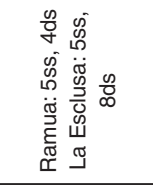 \\
\hline 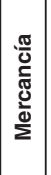 & 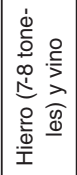 & 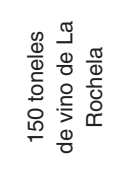 & 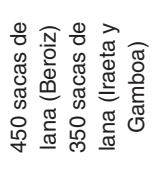 & & 㞼 & 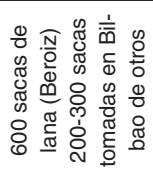 \\
\hline 号 & 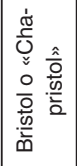 & 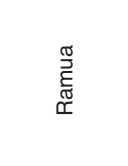 & 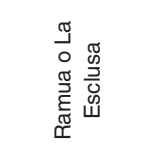 & 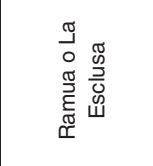 & 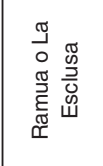 & 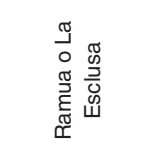 \\
\hline 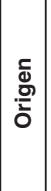 & 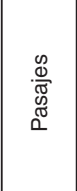 & 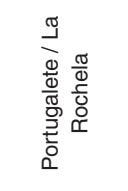 & 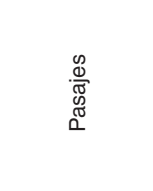 & 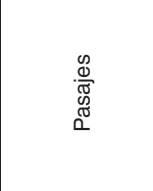 & & 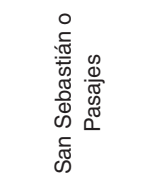 \\
\hline $\begin{array}{l}0 \\
\underset{\mathbf{m}}{2}\end{array}$ & 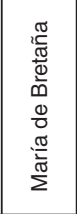 & 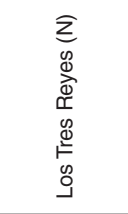 & 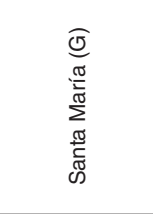 & 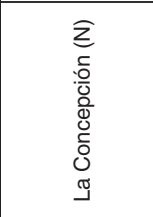 & 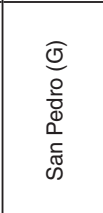 & 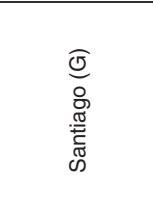 \\
\hline 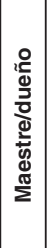 & 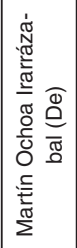 & 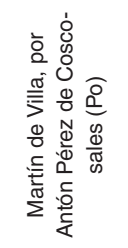 & 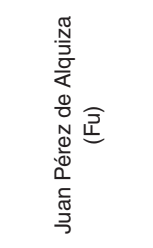 & 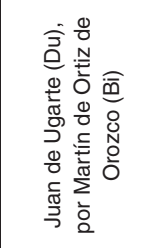 & 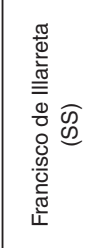 & 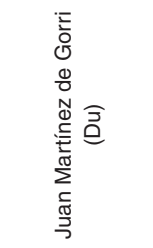 \\
\hline 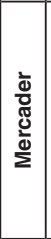 & 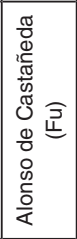 & 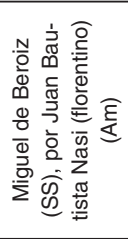 & 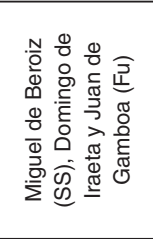 & 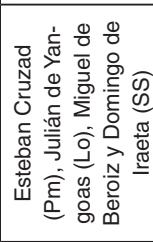 & 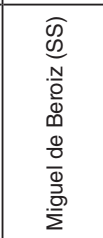 & 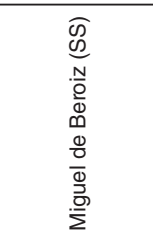 \\
\hline 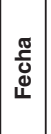 & 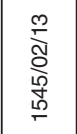 & 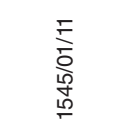 & 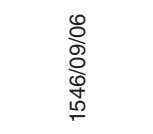 & $\begin{array}{l}\hat{\imath} \\
\frac{1}{2} \\
\stackrel{5}{+} \\
\stackrel{5}{0}\end{array}$ & 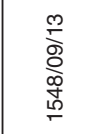 & 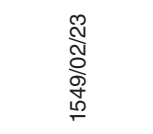 \\
\hline : & $\mathscr{8}$ & षे & $\bullet$ & 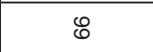 & $\hat{\theta}$ & $\stackrel{\infty}{0}$ \\
\hline
\end{tabular}

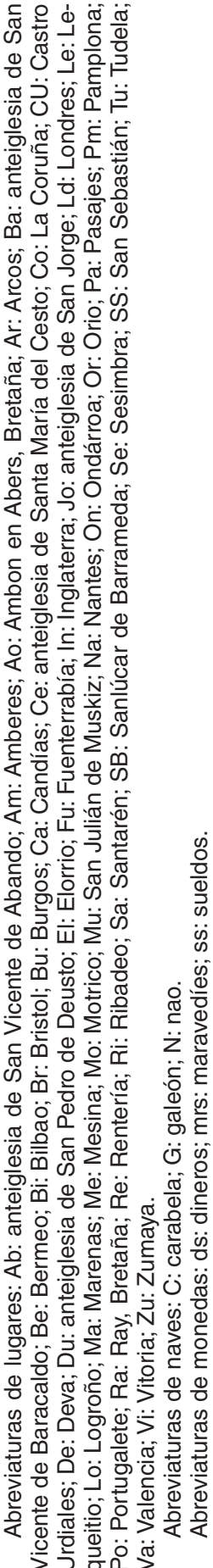


